\title{
MATHEMATICS ACHIEVEMENT IN THE SECONDARY HIGH SCHOOL CONTEXT OF STEM AND NON-STEM SCHOOLS
}

\author{
A Dissertation \\ by \\ ALI BICER \\ Submitted to the Office of Graduate and Professional Studies of \\ Texas A\&M University \\ in partial fulfillment of the requirements for the degree of \\ DOCTOR OF PHILOSOPHY
}

\begin{abstract}
Chair of Committee, Mary M. Capraro
Co-Chair of Committee, Robert M. Capraro

Committee Members, Dianne Goldsby Wen Luo

Head of Department, Lynn M. Burlbaw
\end{abstract}

August 2016

Major Subject: Curriculum and Instruction

Copyright 2016 Ali Bicer 


\begin{abstract}
The primary purpose of the research conducted during this dissertation study is to explore how students who attended ISHSs performed on the mathematics high-stakes state test compared to their corresponding peers who attended traditional public high schools in Texas. All three studies included in this dissertation used quantitative data (i.e., state standardized test scores) to investigate whether students' mathematics performance differs by high school types: STEM and non-STEM. The research for the first article employed one year of state-based data and focused on the comparison of STEM and non-STEM high schools in terms of students' mathematics achievement. The second article employed a longitudinal assessment of students' mathematics achievement to observe how students' initial mathematics scores and their growth rate differ by their high school type as STEM and non-STEM. Research conducted for the third article also used longitudinal state-based data to examine how Hispanic students' mathematics achievement in ISHSs compares to their Hispanic counterparts in traditional public schools.

Results from the first study revealed that Hispanic students who participate in TSTEM academies statistically significantly $(p<.05)$ performed better in mathematics at the end of grade 11 than did Hispanic students who participated in traditional public high schools when controlling for gender and SES. The second study revealed female students' mathematics growth rate in T-STEM academies was statistically significantly higher than female students' mathematics growth rate in traditional public high schools
\end{abstract}


controlling for ethnicity and SES. The third study's findings indicated that female Hispanic students in T-STEM academies statistically significantly $(\mathrm{p}<.05)$ outperformed female Hispanic students in comparison schools on their mathematics growth rate.

Overall, results from this dissertation study yielded that T-STEM academies are most helpful for Hispanic students, and especially for female Hispanic students, in Texas. The findings of this dissertation are important because increasing the number of underrepresented students who major in STEM, which is needed to maintain the United States' scientific leadership and economic power in the global world, can be possible by establishing more inclusive STEM schools in high Hispanic populace locations. 


\section{DEDICATION}

My parents, Cidem Bicer and Cahit Bicer,

Who instilled in me the love of learning at an early age and provided the opportunity for me to pursue a college degree;

My lovely wife, Aysenur,

Who has supported my quest for knowledge throughout almost 7 years of marriage;

My precious daughters, Elif, Nursena, Deniz, and Fatima

Who make my life more enjoyable;

My handsome son, Ahmet Kaan

Who already makes my life more enjoyable;

My sister and my brother, Derya and Deger

Who cheered me on in my studies. 


\section{ACKNOWLEDGEMENTS}

Many thanks go to my wonderful committee, who guided me in my research. In addition, each one made unique contributions to my education and has mentored me in various aspects of my academic career.

In particular, I would like to express my deepest gratitude to my chair and cochair, Dr. Mary M. Capraro and Dr. Robert M. Capraro, for the countless hours spent guiding me in research methods, for teaching me how to write an academic paper, and for encouraging me to have various types of academic products throughout my doctoral education.

I am also thankful to my committee members, Dr. Dianne Goldsby and Dr. Wen Luo, for their invaluable suggestions. Dr. Dianne Goldsby not only encouraged me to make my doctoral first priority, but also supported me in teaching undergraduate classes and gave me numerous opportunities to advance my teaching skills. Dr. Wen Luo continually taught me how to conduct advance quantitative models in education, and gave me feedback and ideas when I needed them.

Special thanks also go to the Aggie STEM center, which provided financial support to purchase the data set. I would like to thank my friend, Bilgin Navruz for his help in data analysis process. Also, I would like to thank Celise Rice, who cheerfully proofread all my work for English grammar and APA corrections.

Finally, thanks are in order once again to my wife for her great patience and love. 


\section{NOMENCLATURE}

$\begin{array}{ll}\text { AP } & \text { Advance Placement } \\ \text { CTE } & \text { Career and Technical Education } \\ \text { ELP } & \text { English Language Proficiency } \\ \text { HLM } & \text { Hierarchical Linear Modeling } \\ \text { ISHSs } & \text { Inclusive STEM High Schools } \\ \text { NAEP } & \text { National Assessment of Educational Progress } \\ \text { NRC } & \text { National Research Council } \\ \text { NSB } & \text { National Science Board } \\ \text { PBL } & \text { Project Based Learning } \\ \text { PCAST } & \text { President's Council of Advisors on the Science and Technology } \\ \text { PISA } & \text { Programme for International Student Assessment } \\ \text { SAT } & \text { Scholastic Aptitude Test } \\ \text { SAS } & \text { Statistical Analysis System } \\ \text { SES } & \text { Socio-Economic Status } \\ \text { SJR } & \text { SCImago Journal Rank } \\ \text { SNIP } & \text { Source Normalized Impact per Paper } \\ \text { SSCI } & \text { Social Science Citation Index } \\ \text { STEM } & \text { Texas Assessment Knowledge and Skills } \\ \text { ECHS } & \\ \text { TAKS } & \end{array}$


TEA

TIMSS

T-STEM
Texas Education Agency

Trends in International Mathematics and Science Study

Texas STEM Academy 


\section{TABLE OF CONTENTS}

Page

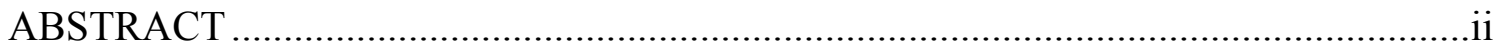

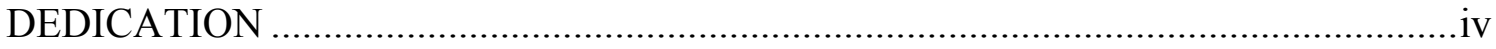

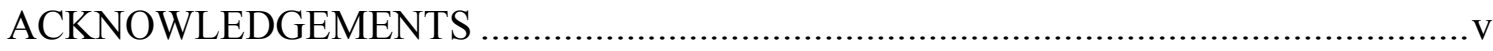

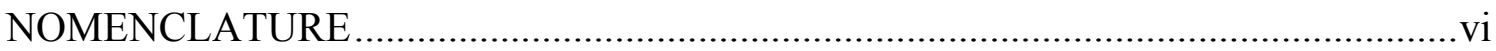

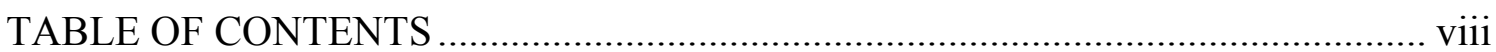

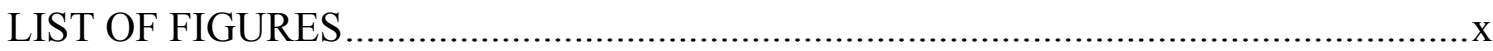

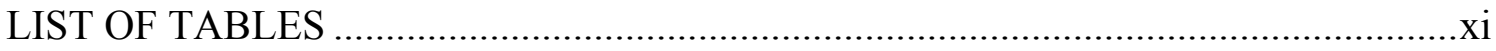

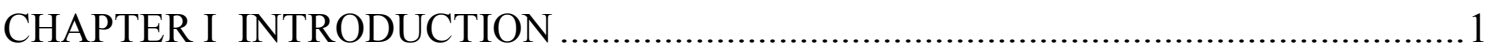

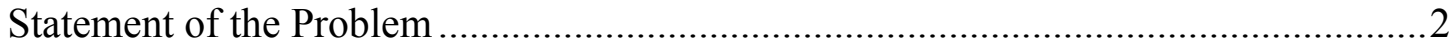

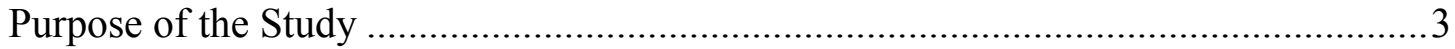

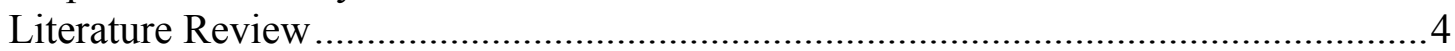

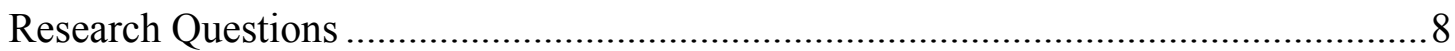

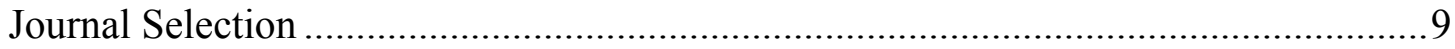

Article 1: STEM Schools vs. Non-STEM Schools: Comparing Students'

Mathematics State Based Test Performance ................................................................11

Article 2: STEM Schools vs. Non-STEM Schools: Comparing Students'

Mathematics Growth Rate on High-Stakes Test Performance......................................15

Article 3: STEM Schools vs. Non-STEM Schools: Examining Hispanic Students'

Mathematics Achievement ....................................................................................19

CHAPTER II STEM SCHOOLS VS. NON-STEM SCHOOLS: COMPARING STUDENTS MATHEMATICS STATE BASED TEST PERFORMANCE ……............23

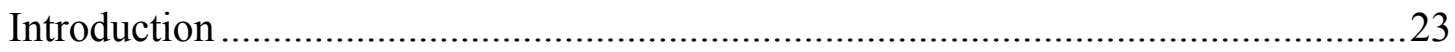

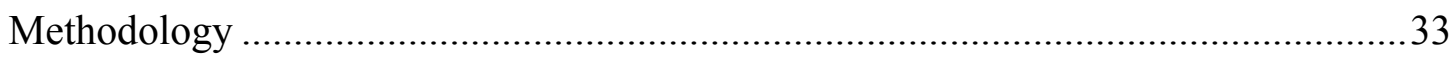

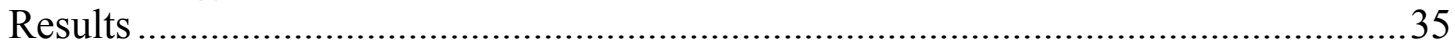

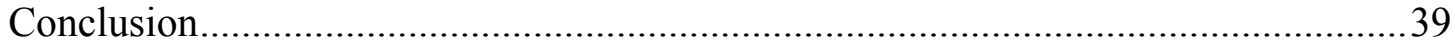


CHAPTER III STEM SCHOOLS VS. NON-STEM SCHOOLS: COMPARING STUDENTS' MATHEMATICS GROWTH RATE ON HIGH-STAKES TEST PERFORMANCE

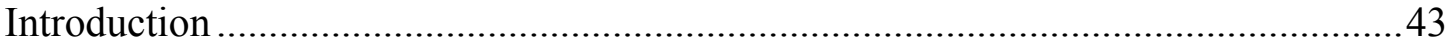

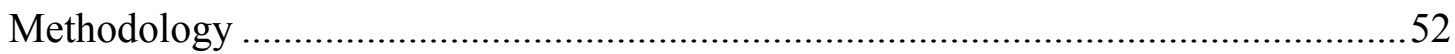

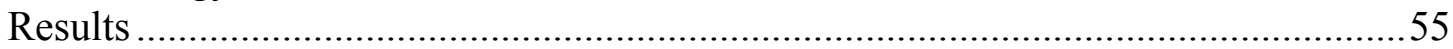

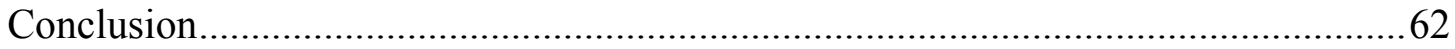

CHAPTER IV STEM SCHOOLS VS. NON-STEM SCHOOLS: EXAMINING HISPANIC STUDENTS' MATHEMATICS ACHIEVEMENT .................................67

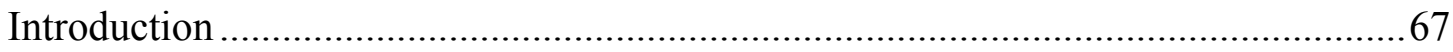

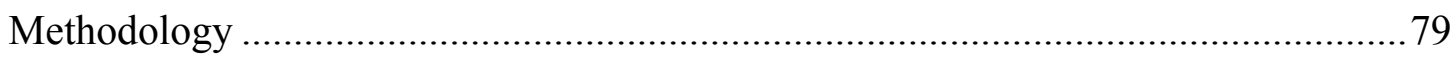

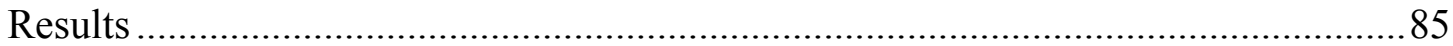

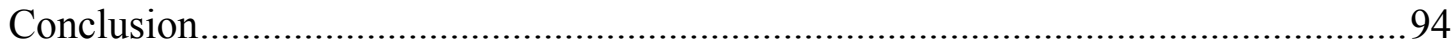

CHAPTER V SUMMARY AND DISCUSSION ................................................... 98

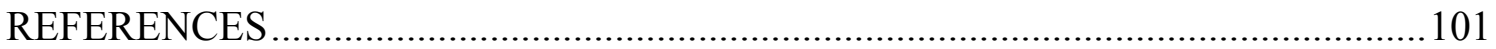

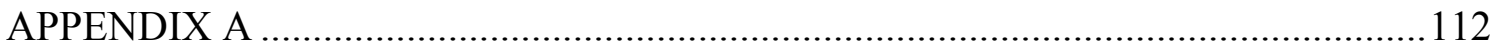

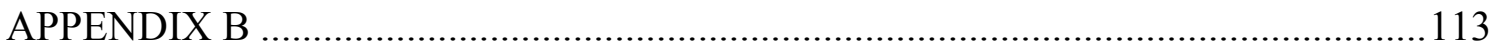




\section{LIST OF FIGURES}

Page

Figure 1. Conceptual framework for the present study ........................................29

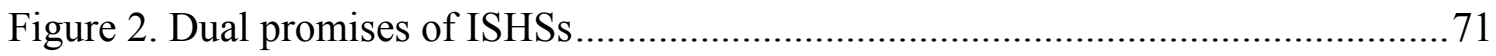

Figure 3. The elements of successful K-12 STEM programs .................................... 73

Figure 4. Distribution of propensity score matching............................................... 81

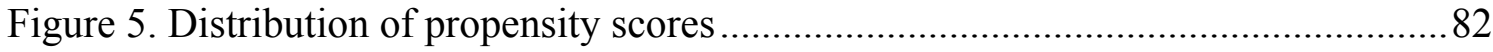




\section{LIST OF TABLES}

Page

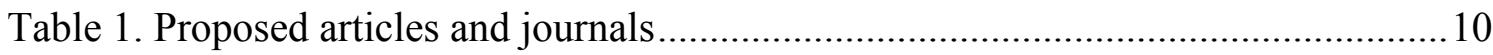

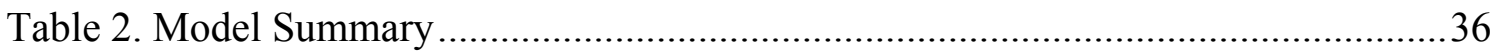

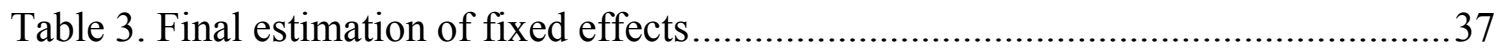

Table 4. Final estimation of fixed effects for intercept ...........................................58

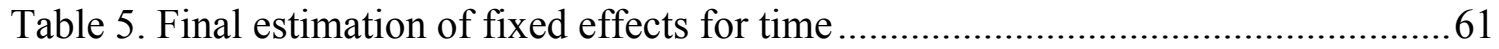

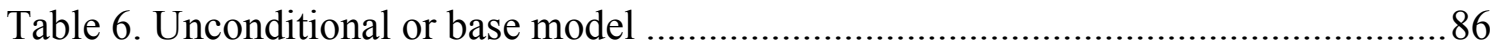

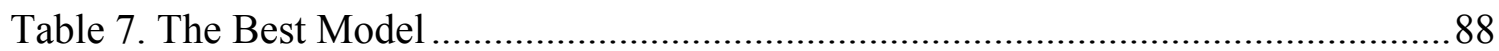

Table 8. Final Estimation of Fixed Effects for Intercept............................................90

Table 9. Final Estimation of Fixed Effects for Time ................................................... 92 


\section{CHAPTER I}

\section{INTRODUCTION}

STEM education refers to the teaching and learning practices in the disciplines of science, technology, engineering, and mathematics. STEM education has come front and center for educators and policymakers in the United States, and many reports have recognized this critical issue. These reports, such as the America Competes Act (2007), Rising above the Gathering Storm (2007), and the President's Council of Advisors in Science and Technology (2010), suggested placing more importance on STEM education in order to ensure the nation's future global economic power and scientific leadership. These reports focused on STEM education because international indicators such as PISA and TIMSS revealed that American youth fall behind their peers from other developed countries in their science and mathematics abilities (Russell, Hancock, \& McCulloguh, 2007). Secretary of Education Arne Duncan (2012) responded to the TIMSS results in a statement saying, "Given the vital role that science, technology, engineering, and math play in stimulating innovation and economic growth, it is particularly troubling...that students in Singapore and Korea are far more likely to perform at advanced levels in science than U.S. students" (Internet). As expected, the National Science Board reported a shortage of STEM workers in the nation's near future (National Science Board, 2010). Later, the National Research Council (2011) stated three goals that need to be achieved in order to maintain the nation's current economic power and scientific leadership. First, the number of people who have advanced degrees in STEM majors, such as engineers, 
doctors, and scientists, needs to be expanded. Second, the number of people who enter the STEM workforce but do not hold advanced STEM degrees needs to be expanded because the majority of STEM careers do not require advanced STEM degrees, but they require vocational or technical skills. Third and lastly, the number of people who are able to understand basic science and mathematics concepts needs to increase even if these people do not follow STEM career pathways. To achieve these three goals, many interventions were suggested including designing STEM summer camps, offering more advanced science and mathematics classes, and establishing specialized STEM schools. Among the interventions suggested to achieve the three goals for U.S. STEM education, establishing inclusive STEM high schools (ISHSs) was one of the most promising to increase K-12 students' interest in STEM disciplines (NRC, 2011).

\section{Statement of the Problem}

The promising effects of attending ISHSs on students' science and mathematics achievement are prevalent in the media, but little scholarly research has been conducted on these effects (Burton et al., 2014; Means et al., 2013). Subotnik, Tai, Rickoff, and Almorode (2010) also noted that empirical research examining whether students in ISHSs do better in mathematics and science than students in traditional public high schools has been sparse. This is to be expected, though, given that ISHSs are relatively new with few having even graduated their first class of students (Means et al., 2013). There has been some research published focusing on individual schools (Lynch \& Means, 2012) and research with state based data (Gourgey, Asiabanpour, Crawford, Gross, \& Herbert, 2009; Young et al., 2011). In this dissertation, I will not report on 
individual schools because cases of individual schools do not "prove that the same effect will be achieved when the concept is implemented at scale" (Means et al., 2013, p. 3). I

will compare ISHSs with traditional public high schools because "There appears to be no published rigorous, on-site comparative studies of ISHSs designed to make systematic comparisons across ISHSs; between ISHSs and their counterparts; or, that used a set of common measures guided by cohesive research design" (Burton et al., 2014). Means et al. (2013) also pointed out the need for research about ISHSs by suggesting a longitudinal assessment for future research was required to be able to understand the impact of ISHSs on students' mathematics achievement.

\section{Purpose of the Study}

The primary purpose of the research that will be conducted during this dissertation study will be to explore how students who attended ISHSs performed on the mathematics high-stakes state test compared to their corresponding peers who attended traditional public high schools in Texas. All three articles will use quantitative data (i.e., state standardized test scores) to investigate whether students' mathematics performance differs by high school types: STEM and non-STEM. The research for the first article will employ one year of state-based data and focus on the comparison of STEM and nonSTEM high schools in terms of students' mathematics achievement. The second article will employ a longitudinal assessment (2009-2011) of students' mathematics achievement to observe how students' initial mathematics scores and their growth rate differ by their high school type as STEM and non-STEM. Research conducted for the third article will also use longitudinal state-based data to examine how Hispanic 
students' mathematics achievement in ISHSs compares to their Hispanic counterparts in traditional public schools. It is hoped that three proposed articles will fill the existing research gap about the impact of ISHSs on students' mathematics achievement by employing a longitudinal investigation of large-scale data.

\section{Literature Review}

\section{STEM High Schools}

STEM schools are designed to decrease the mathematics and science achievement gaps among various ethnic groups and to increase all K-12 students' mathematics and science scores on both national and international standardized tests (Capraro, Capraro, \& Lewis 2013; Capraro, Capraro, \& Morgan, 2013). There are three types of STEM schools: selective STEM schools, inclusive (i.e., open-admission) STEM schools, and schools with STEM-focused career and technical education (CTE). Selective and inclusive STEM schools are the two most common STEM schools across the United States (NRC, 2011). The curriculum for selective and inclusive STEM schools was designed to improve students' science and mathematics learning by engaging students with hands-on tasks in a collaborative and competitive environment (Gonzalez \& Kuenzi, 2012). There are some differences between these two types of STEM schools in terms of their organization. The clearest distinction between selective STEM schools and inclusive STEM schools is the admission criteria. Selective STEM schools admit only students who are talented in and motivated toward STEM related fields while inclusive STEM schools have no selective admission criteria. Because of the difference between admission criteria of the two STEM school types, inclusive STEM 
schools are considered to serve a broader population (NRC, 2011). Young, House, Wang, and Singleton (2011) noted that "Inclusive STEM schools are predicated on the dual promises that math and science competencies can be developed; and that students from traditionally underrepresented populations need access to opportunities to develop these competencies to become full participants in areas of economic growth and prosperity" (p. 2). Therefore, inclusive STEM schools utilize a unique school structure to achieve the three goals stated by NRC (2011) for K-12 STEM education.

\section{Texas STEM Initiative}

In these three proposed articles, STEM schools were selected from the state of Texas because it has one of the largest inclusive STEM school initiatives in the United States (NRC, 2011). This project, the T-STEM Initiative, was launched in 2006 and continues to grow steadily. The objective of this initiative is to: (a) increase the number of students who follow STEM career pathways; (b) help promote quality school leadership by supporting school redesign efforts, teacher recruitment, and teacher preparation; and (c) assist in the STEM disciplines' long term educational development (Educate Texas, 2014). The T-STEM initiative offers a fundamental approach to advancing studies in STEM disciplines by empowering STEM teachers and inspiring students (Educate Texas, 2014).

STEM schools in the state of Texas, known as Texas STEM (T-STEM) academies, are one aspect of the T-STEM initiative and are defined by a unique "blueprint" that differentiates them from non-STEM schools. One important characteristic of the blueprint is the implementation of innovative instructional methods 
such as project-based learning (PBL), inquiry based learning, and problem based learning. Avery, Chambliss, Pruiett, and Stotts (2010) noted that the STEM blueprint is one of the remarkable characteristics of T-STEM academies that either guides schools in transitioning to becoming T-STEM academies or establishing new T-STEM academies entirely. The blueprint requires that all T-STEM academies have open enrollment and cannot be selective at the time of enrollment. In addition, the blueprint indicates that each T-STEM academy's student body needs to be comprised of at least $50 \%$ of students who are economically disadvantaged and/or students who come from traditionally underrepresented subpopulations (i.e., female, African American, Hispanic, and disabled) (Avery et al., 2010; Young et al., 2011).

As of 2014, there have been 75 T-STEM academies serving 40,000 students in either grade bands 6-12 or 9-12. T-STEM academies were separated into seven regions, and each region incorporated a STEM center. These seven T-STEM centers are located at universities and regional education service centers and designed to render academic assistance to the T-STEM academies. The T-STEM centers build partnerships with industry and business in order to provide resources for T-STEM academies. More than 2,800 teachers in STEM disciplines receive assistance from these seven T-STEM centers. This assistance includes but is not limited to creating new STEM instructional materials and providing high-quality professional development (Educate Texas, 2014).

\section{Success of T-STEM Designation}

A study conducted by Young et al. (2011) used state based data to reveal the effects of attending T-STEM academies compared to the effects of attending traditional 
high schools in Texas. The findings revealed that students who attended T-STEM academies performed better in mathematics and science than did students who attended traditional public high schools; however, the Cohen's $d$ effect sizes of attending TSTEM academies reported by this study ranged from 0.12 to 0.17 . Specifically, $9^{\text {th }}$ graders in T-STEM academies performed better in mathematics compared to $9^{\text {th }}$ graders in traditional public schools (Gourgey et al., 2009; Young et al., 2011). Similarly, $10^{\text {th }}$ graders attending T-STEM academies performed better in mathematics and science than did their peers in comparison schools (Young et al., 2011). Young et al. (2011) also reported that 9th graders in T-STEM academies were 1.8 times more likely to meet the TAKS benchmarks in the sections of reading and mathematics than were their counterparts in traditional public schools. Similar results were reported for $10^{\text {th }}$ graders as students in T-STEM academies were 1.5 times more likely than their traditional public school peers to meet the TAKS benchmarks on the reading, mathematics, science, and social science sections. Gourgey et al. (2009) examined students' academic patterns of change over time in T-STEM academies and found that attending T-STEM academies had different effects on students based on their ethnic background and SES. These results revealed that while attending T-STEM academies increased Hispanic students' mathematics scores, a slight decrease was observed for African American and White students. Further, the results showed that students from low-SES backgrounds increased their mathematics scores compared to scores in previous years. 


\section{Research Questions}

Research proposed for this dissertation study is mainly focused on investigating how students who attended T-STEM academies performed on the mathematics section of the Texas Assessment of Knowledge and Skills (TAKS) compared to their corresponding peers who attended traditional public schools in Texas. Specific questions that will be answered by the research being conducted include:

Articles 1 and 2 Research Questions Published (see table 1)

1. How do students who are enrolled in T-STEM academies perform on TAKS mathematics compared to their corresponding peers who were enrolled in traditional public high schools in Texas?

2. Controlling for students' demographics (gender, ethnicity, and SES), what is the effect of school types (STEM schools and non-STEM schools) on students' mathematics achievement?

3. How does initial student mathematics performance differ by school types (STEM schools and non-STEM schools)?

4. What are the mathematical benefits for students who attended T-STEM academies for three years as compared to their non-STEM counterparts? Article 3 Research Questions

5. Do Hispanic students who attend T-STEM academies perform better on mathematics high-stakes tests than Hispanic students who attended traditional high schools at the end of grade 9 ? 
6. What are the mathematical benefits for Hispanic students who attend TSTEM academies for three years as compared to their Hispanic counterparts who attend traditional public high schools?

\section{Journal Selection}

Among the three proposed articles, two of them were already published in academic journals. The first article was published in the International Journal of Global Education in 2014. The second article was published in the International Journal on New Trends in Education and Their Implications in 2015. To submit the third article for publication, two potential journals were selected. These journals were selected based on two major criteria. Initially, the journals were selected based on whether the topic of the article was relevant to the scope and expected readers of the journals. Further, two journals (see Table 1) were selected based on their impact factors and the prestige of the editorial board. The Journal Citation Reports Social Sciences Citation Index (JCRSSCI), Thompson Reuters, and Scopus database were used to retrieve SCImago Journal Rank (SJR) and Source Normalized Impact per Paper (SNIP) for the journals. The journal web page was referenced for information such as acceptance rate, review type, and other manuscript requirements. 
Table 1

Proposed Articles and Journals

\begin{tabular}{|c|c|c|}
\hline Proposed Article & Proposed Journal \#1 & Proposed Journal \#2 \\
\hline $\begin{array}{l}\text { Article 3: STEM Schools } \\
\text { vs. Non-STEM Schools: } \\
\text { Examining Hispanic } \\
\text { Students' Mathematics } \\
\text { Achievement }\end{array}$ & $\begin{array}{l}\text { Journal of Latinos and } \\
\text { Education } \\
\text { - } \quad \text { Acceptance rate: } 35 \% \\
\text { - } \quad \text { Impact and ranking } \\
\text { (SJR/SNIP): 0.39/0.698 } \\
\text { - Editor in chief: Enrique } \\
\text { G. Murillo } \\
\text { - Publisher: Taylor \& } \\
\text { Francis } \\
\text { - Type of review: Peer } \\
\text { Review } \\
\text { - Manuscript length: } 20-30 \\
\text { pages, double space }\end{array}$ & $\begin{array}{l}\text { Educational Studies in } \\
\text { Mathematics } \\
\text { - } \quad \text { Acceptance rate: } 25 \% \\
\text { - Impact and ranking } \\
\text { (SJR/SNIP): } 0.032 / 1.942 \\
\text { - Editor in chief/Associate } \\
\text { editors: Norma Presmeg } \\
\text { - Publisher: Springer } \\
\text { - Type of review: Peer } \\
\text { Review } \\
\text { - Manuscript length: } 16-20 \\
\text { pages }\end{array}$ \\
\hline
\end{tabular}

Article 2: STEM Schools

Published. The full citation for this article is:

vs. Non-STEM Schools:

Comparing Students'

Mathematics Growth Rate

on High-Stakes Test

Performance

Bicer, A., Navruz, B., Capraro, R. M., Capraro, M. M., Oner, T. A., \& Boedeker, P. (2015). STEM schools vs. non-STEM schools: Comparing students' mathematics growth rate on high-stakes test performance.

International Journal of New Trends in Education and Their Implications, 6(1), 138-150.

Article 1: STEM Schools vs. Non-STEM Schools:

Comparing Students'

Published. The full citation for this article is:

Mathematics State Based

Bicer, A., Navruz, B., Capraro, R. M., \& Capraro, M. M. (2014). STEM schools vs. non-STEM schools:

Test Performance Comparing students' mathematics state based test performance. International Journal of Global Education, 3(3), 8-18. 


\section{Article 1: STEM Schools vs. Non-STEM Schools: Comparing Students' Mathematics State Based Test Performance}

\section{Background}

STEM education refers to teaching and learning in the disciplines of science, technology, engineering, and mathematics. From a broad perspective, STEM education in both formal and informal settings has been considered a set of activities in which students engaged (Gonzalez \& Kuenzi, 2012). STEM education has captured the attention of educators because STEM practices (e.g., project-based learning and inquirybased learning) in K-12 classrooms enable students to relate their knowledge, skills, and beliefs across STEM disciplines (International Technology Education [ITEA], 1999), thus promising more meaningful science and mathematics learning for K-12 students. Besides researchers and educators, policymakers have also emphasized the importance of K-12 STEM education for the country's future economic competitiveness in the global market. Several reports by the National Academy of Sciences, National Academy of Engineering, and Institute of Medicine (2011a) have already linked the importance of K-12 STEM education to maintaining the United States' current scientific leadership and economic power.

In response to the importance of STEM education for the United States' scientific leadership, the United States' President Obama has launched the Educate and Innovate program for the purpose of increasing students' interests toward STEM-related majors by cultivating STEM literacy in K-12 education. Buxton (2001) investigated the role of K-12 education on students' interest in STEM related subjects. Results from this 
study revealed that the K-12 education years are vitally important in developing students' interest in one of the STEM- related subjects. Therefore, increasing K-12 students' interest in STEM-related disciplines is essential for leading more students to pursue STEM career pathways in postsecondary education settings.

\section{Cultivating STEM Interest in K-12}

Most researchers have found students' interest to be one of the most promising factors influencing students' future career plans (Beiber, 2008; Calkins \& Welki, 2006; Kuechler, Mcleod, \& Simkin, 2009). Interest was defined by Beiber (2008) as "relatively stable preferences that are focused on objects, activities, or experiences" (p. 1). Kuechler et al. (2009) suggested that students choose certain majors only when they are exposed to related real world activities. It is students' experiences during the K-12 education years that lead them to have more positive attitudes toward certain majors. Thus, engaging students in real-world STEM activities has increased students' interests in STEM related disciplines (Sahin, 2013). For example, Sahin, Erdogan, Morgan, Capraro, and Capraro (2013) investigated the relationship between high school students' SAT scores, course enrollment, and pursuit of major at the college level. Results from this study revealed that students with higher SAT mathematics scores were more likely to choose STEM related majors in their college years. Additionally, students involved in advanced placement (AP) courses pursued more STEM related majors than students who did not. In summary, students' experiences during the K-12 education years were positively correlated with their course selection, overall achievement, and persistence in 
a certain field (e.g., in one STEM fields) (Beiber, 2008). Therefore, investigating what types of schools (e.g., STEM schools vs. non-STEM schools) develop students' mathematics and science interests and, in turn, increase their mathematics and science achievement is vitally important.

Achieving the goals for the nation's K-12 STEM education is possible by incorporating STEM for all students. Beiber (2008) noted that students'school experiences were positively correlated with their science and mathematics course selection and achievement, as well as their persistence in these fields. Therefore, in this proposed article, it is predicted that participation in STEM schools may increase students' mathematics achievement because these schools do the following: a) emphasize the importance of STEM disciplines, b) target underserved populations, c) implement rigorous science and mathematics curricula, d) have more STEM instructional time, e) provide more resources for STEM teaching and learning activities, and f) hire quality science and mathematics teachers (NRC, 2011).

\section{Method}

Participants. The sample will consist of 1,887 students (940 from T-STEM schools and 947 from non-STEM schools) who received a TAKS mathematics score in 2011. Students will be excluded from the study if they did not have a TAKS mathematics score in 2011. Students' $11^{\text {th }}$ grade mathematics TAKS scale scores will be used as a measurement of students' mathematics achievement. Students' gender, ethnicity, and SES background will be added as predictors to the model in order to 
determine the most promising effects of STEM schools.

Data sources. In this quantitative research project, student and school-level data about students who participated in inclusive T-STEM high schools, as well as matched students who participated in non- STEM high schools, will be obtained from the TEA website. This statewide analysis will be based upon 36 schools, of which 18 will be TSTEM academies and 18 will be matched non- STEM schools. In this study, only $18 \mathrm{~T}$ STEM academies of 65 T-STEM academies will be selected because the selected schools need to have the criteria of being turned into inclusive STEM schools before or during the 2008-2009 academic year. Thus, the present study will include only students who participated in STEM academies for at least three years.

Data analysis. This study will use hierarchical linear modeling (HLM) techniques to construct a two-level model for analysis. This technique allows the simultaneous estimation of between-schools variables (STEM schools and non-STEM schools), and within-school level variables (students' mathematics TAKS scale scores, ethnicity, gender, and SES). A series of model fitness will be estimated by using HLM software, and this procedure will result in the best model with specific student and school-level variables. Based on a theoretical and empirical consideration reported by NRC (2011), each student-level variable will be added one at a time to the model and will be evaluated for statistical significance. The same procedure will be followed for the school-level predictor, and its effects will be also evaluated for statistical significance. 


\section{Article 2: STEM Schools vs. Non-STEM Schools: Comparing Students' Mathematics Growth Rate on High-Stakes Test Performance}

\section{Background}

Researchers conducted both qualitative and quantitative studies to explore the effects of attending T-STEM academies on students' science, reading, social science, and mathematics achievement (Capraro et al. 2013; Gourgey et al., 2009; Stotts, 2011; Young et al., 2011). The qualitative (Gourgey et al., 2009) and quantitative studies (Capraro et al. 2013; Stotts, 2011; Young et al., 2011) regarding T-STEM academies indicated promising effects of T-STEM academies on students' academic achievement.

To determine if the positive effects of attending T-STEM academies on students' academic achievement continue throughout their secondary education, a longitudinal method was used (Capraro et al. 2013; Young et al., 2011). Applying a longitudinal method enables researchers to characterize patterns of change in students' scores over time, which includes both the average trajectory and the variability of each student's trajectories. To compare students' academic achievement in terms of their school types (T-STEM academies and non-STEM schools [traditional public schools]), researchers applied various comparison techniques, such as exact matching or propensity score matching. Results from these studies indicated that students who were in grade 9 in $\mathrm{T}$ STEM academies achieved slightly higher mathematics scores than did their peers in the comparison schools. Similarly, results showed that students who were in grade 10 in TSTEM academies received higher mathematics and science scores than did their peers in the comparison schools. These findings showed a difference favoring T-STEM 
academies, but the Cohen's $d$ effect size reported ranged from 0.12 to 2.03. Results from Young et al.'s study (2011) yielded that students who were in grade 9 and attended TSTEM academies were 1.8 times more likely to meet the benchmarks of TAKS reading and mathematics than were their counterparts in comparison schools. Likewise, students who were in grade 10 and attended T-STEM academies were 1.5 times more likely to meet the benchmarks of TAKS reading, mathematics, social science, and science than were their counterparts in comparison schools (Young et al., 2011).

In another attempt to characterize students' academic patterns of change over time in T-STEM academies (Gourgey et al., 2009), students who were in grade 10 and participated in T-STEM academies increased their mathematics and reading high-stakes test results compared to their corresponding scores in grade 9 . Students who were in grade 10 and came from low-SES backgrounds increased their mathematics scores compared to their mathematics scores in grade 9. In terms of ethnic background, Hispanic students who were in grade 10 showed the largest increase within any of the ethnic groups in their mathematics scores compared to their mathematics scores at grade 9.

Researchers mostly focused on students' test scores to compare the success of TSTEM academies compared to matched schools; however, NRC (2011) noted that students' test scores do not convey the complete story of success. In response, researchers also examined the relationship between school types (T-STEM and nonSTEM) and dropout rate as a measure of success. Results revealed that students who attended T-STEM academies were 0.8 times less likely to be absent from school than 
were their peers in comparison schools (Young et al., 2011; cf. Capraro et al. 2014). Students who attended T-STEM academies were more comfortable with STEM related disciplines and more likely to pursue a college degree, and more female students took advanced placement (AP) courses (Stotts, 2011). Another important finding revealed that one of the high schools changed its rating from Academically Unacceptable to Academically Acceptable as a result of students' academic achievement scores on highstakes tests a year after the school turned into a T-STEM academy. After schools became T-STEM academies, more students enrolled in college level courses than they did when their schools were non-STEM schools (Stotts, 2011). The T-STEM academies were more successful across a wide range of variables including test scores, attitude, truancy, and college matriculation.

The present study will apply a longitudinal method to track students' mathematics success between the years of 2009 and 2011. Researchers have already applied a longitudinal method to characterize students' success between the years of 2007 and 2009 (Young et al., 2011). However, these studies were conducted in the earlier stage of the newly established T-STEM academies. Therefore, the present study will involve only schools that turned into T-STEM academies before the 2008-2009 school years. This constraint ensures that the schools have had adequate time to implement STEM-specific curriculum and teaching to show promising effects on students' mathematics achievement. 


\section{Methods}

Participants. The sample will consist of three years of Texas Assessment of Knowledge and Skills (TAKS) mathematics data for 3,026 students, of whom 1,506 attended 18 T-STEM academies and 1,520 attended 18 non-STEM schools in Texas.

The first measurement for the sample will be taken in 2009 at the end of students' $9^{\text {th }}$ grade year, and the last measurement for the same students will be taken in 2011 at the end of their $11^{\text {th }}$ grade year.

Data sources. In this quantitative research project, student and school-level data about students who attended inclusive stand-alone T-STEM academies, as well as matched students who attended non-STEM high schools, will be obtained from the TEA website. This statewide analysis will be based upon 36 schools, of which 18 will be TSTEM academies and 18 will be matched non- STEM (traditional public) schools. In this study, only 18 of the 65 T-STEM academies will be selected because of the selection criteria of becoming an inclusive T-STEM school during or before the 20082009 school year and because of the designation of the academy (stand-alone or schoolwithin-school).

Data analysis. Hierarchical linear modeling (HLM) will be used to construct a three-level model for analysis. Level-1 will be the repeated measures, which are nested within students. Level-2 will be the students who are further nested within school types. Level-3 will be the school types (STEM and non-STEM). This three-level model will be used in the present study to characterize patterns of change in students' measures over time, which will include both the average trajectory and the variability of students' 
trajectories. This technique also allows the simultaneous estimation of between-schools variables (STEM schools and non-STEM schools), within-school level variables (ethnicity, gender, and SES), and the variances of students' repeated measures. A series of model fit indices will be estimated by using HLM software, and this procedure will result in the best model.

\section{Article 3: STEM Schools vs. Non-STEM Schools: Examining Hispanic Students' Mathematics Achievement}

\section{Background}

Traditionally, the purpose of science, technology, engineering, and mathematics (STEM) schools has been to provide advanced STEM coursework to students who are talented and gifted in STEM disciplines (Burton, Lynch, Behrend, \& Means, 2014; Means et al., 2013; Young et al., 2011). Recently, a new and innovative approach to STEM school design is emerging: inclusive STEM high schools (ISHSs). Unlike the original STEM schools, known as selective STEM schools, ISHSs accept all students regardless of their previous academic achievement and interest in science and mathematics (Means et al., 2013; NRC, 2011). This new school design for STEM education is one of the suggestions proposed by the NRC (2011), which noted that ISHSs possess great potential for addressing the following STEM education needs in the United States: a) increasing the number of students interested in STEM careers that require advanced degrees, $b$ ) increasing the number of students interested in the STEM careers that require vocational skills, and c) increasing the overall science and mathematics literacy of the entire population (NRC, 2011). Achieving these goals is 
critical to the United States maintaining its current global economic power and scientific leadership (NRC, 2011).

The focus of the present study is on the ISHS initiative in Texas, with a narrowed focus on the factors influencing underrepresented students' STEM preparation in ISHSs. As a result of the Texas STEM (T-STEM) Initiative, seven T-STEM academies were founded in Texas during the 2006-07 academic year. As of the 2013-14 school year, there were 70 T-STEM academies in Texas serving 40,000 students. There were seven grant-funded T-STEM centers established for the purpose of supporting T-STEM academies. Their mission is to help create innovative instructional models and provide professional development for teachers (Texas Education Agency, 2014). T-STEM academies were designed and implemented under the guidance of a detailed blueprint that requires the academies to: a) provide college preparatory curriculum, b) create real world relevant instruction, c) set a strong academic system, d) offer a wide range of STEM coursework, and e) support underrepresented students and prepare them for STEM college programs and careers (NRC, 2011; Young et al., 2011). Support for underrepresented students is a unique attribute of ISHSs and accounts for the primary difference between the two types of STEM schools.

The main purpose of the present study will be to investigate how Hispanic students' mathematics achievement in ISHSs compares to that of their counterparts in traditional public schools. This study will be limited to Hispanic students for the following reasons: 1) Hispanic students in Texas had the largest population percentage of total enrollment (50.3\%) in 2010-11 (TEA, 2011), and 2) recent research has 
demonstrated that Hispanic students are the only ethnic group increasing in mathematics achievement by their enrollment in T-STEM academies (Gourgey et al., 2009). Therefore, the purpose of this proposed article will be to compare Hispanic students' mathematics performance in terms of their school types (T-STEM academies and nonSTEM schools).

\section{Methods}

Participants. The sample for this proposed study will be students (389 from TSTEM academies and 1,036 from traditional public schools) who attended their respective schools for at least three years and received a TAKS mathematics score in 2009 and 2011. Students who did not receive a TAKS mathematics scores in either 2009 or 2011 will be excluded in the study. Students will be also excluded if they transferred into T-STEM academies from a non-STEM school or transferred into a non-STEM school from T-STEM academies. This exclusion ensures that participants in the present study who attended T-STEM academies received at least three years of STEM education and were not exposed to any other school interventions during their high school years. To ensure matched comparison schools did not adopt any school level interventions, schools that implemented any intervention (e.g., Early College High School (ECHS) intervention) will be excluded from the matched school list. Students' TAKS mathematics scores will be used as an outcome estimate of students' mathematics performance.

Data sources. The data will include students' and schools' information pulled from the state accountability assessment, Texas Assessment of Knowledge and Skills 
(TAKS), which provided empirical data (2009 to 2011). Reporting reliability coefficients related to students' mathematics performance will be used to estimate to what extent the data were consistent (Huck, 2008). The reliability coefficients of mathematics scores on the TAKS assessment was reported as ranging from .82 to .88 (TEA, 2008; Zucker, 2003). The first measurement for the sample will be collected at the end of the students' $9^{\text {th }}$ grade year in 2009 , and the last measurement for the same students was taken at the end of the students' $11^{\text {th }}$ grade year in 2011.

Data analysis. To examine mathematics performance differences at the end of grade 9 between Hispanic students who attended T-STEM academies and Hispanic students who attended traditional high schools, and the growth rate of mathematics performance from grade 9 to grade 11, a three-level growth model in the Hierarchical Linear Modeling (HLM) technique will be applied to analyze student and school-level variables simultaneously (Hox, 2002). Level-1 will be the repeated measures of students' mathematics scores, which are nested within students. Level-2 will be the students who are further nested within school types. Level-3 will be the school types of STEM and non-STEM schools. Using a three-level model will allow the researcher to analyze patterns of change in students' measures over time, which include both average trajectory and the variability of students' trajectories. 


\section{CHAPTER II}

\section{STEM SCHOOLS VS. NON-STEM SCHOOLS: COMPARING STUDENTS MATHEMATICS STATE BASED TEST PERFORMANCE *}

\section{Introduction}

STEM education refers to teaching and learning in the disciplines of science, technology, engineering, and mathematics. From a broad perspective, STEM education in both formal and informal settings has been considered a set of activities in which students engaged (Gonzalez \& Kuenzi, 2012). STEM education has become a pivotal topic for educators. The foremost reason why STEM education has captured the attention of educators is because STEM practices (e.g., Project-Based Learning and inquiry-based learning) in K-12 classrooms enable students to relate their knowledge, skills, and beliefs across STEM disciplines (International Technology Education [ITEA], 1999), thus promising more meaningful science and mathematics learning for K-12 students. Besides researchers and educators, governors have also emphasized the importance of K-12 STEM education for the country's future economic competitiveness in the global market. Several reports by the National Academy of Sciences, National Academy of Engineering, and Institute of Medicine (2011a) have already linked the importance of K-12 STEM education to maintaining the United States' current scientific leadership and economic power.

\footnotetext{
* Reprinted with permission from "STEM school vs. non-STEM schools: Comparing Students Mathematics State Based Test Performance" by Ali Bicer, Bilgin Navruz, Robert M. Capraro, \& Mary M. Capraro, 2014. Turkish Journal of Education, 3(3), 8-18, Copyright [2014] by International Journal of Global Education.
} 
The success of STEM disciplines plays a vital role for the country's future in the competitive global market (President's Council of Advisor on Science and Technology (PSAT), 2010). In response to the importance of STEM education for the United States' scientific leadership, the United States' President Obama has launched the Educate and Innovate program for the purpose of increasing students' interest toward STEM-related majors by cultivating STEM literacy in K-12 education. Buxton (2001) investigated the role of K-12 education on students' interest in STEM related subjects. Results from this study revealed that the K-12 education years are vitally important in developing students' interest in one of the STEM-related subjects. Therefore, increasing K-12 students' interest in STEM-related disciplines is essential for leading more students to pursue STEM career pathways in postsecondary education settings.

\section{Cultivating STEM Interest in K-12}

Most researchers have found interest to be one of the most promising factors influencing students' future career plans (Beiber, 2008; Calkins \& Welki, 2006; Kuechler, Mcleod, \& Simkin, 2009). Interest was defined by Beiber (2008) as "relatively stable preferences that are focused on objects, activities, or experiences" (p. 1). Kuechler et al. (2009) suggested that students choose certain majors only when they are exposed to related real-world activities. It is students' experiences during K-12 education years that lead them to have more positive attitudes toward certain majors. Thus, engaging students in real-world STEM activities has increased students' interests in STEM related disciplines (Sahin, 2013). For example, Sahin, Erdogan, Morgan, Capraro, and Capraro (2013) investigated the relationship between high school students' SAT scores, course 
enrollment, and pursuit of major at the college level. Results from this study revealed that students with higher SAT mathematics scores were more likely to choose STEM related majors in their college years. Additionally, students involved in advanced placement (AP) courses pursued more STEM related majors than students who did not. In summary, students' experiences during K-12 education years were positively correlated with their course selection, overall achievement, and persistence in a certain field (e.g., in one STEM fields) (Beiber, 2008). Therefore, investigating what types of

schools (e.g., STEM schools vs. non-STEM schools) develop students' mathematics and science interests and, in turn, increase their mathematics and science achievement is vitally important.

\section{Needs for K-12 STEM Education}

Three main reasons account for U. S. concerns about the state of K-12 STEM education. The first reason is students' science and mathematics test performance as measured by the National Assessment of Educational Progress (NAEP) showed that students were not proficient in mathematics and science (Schmidt, 2011). Additionally, international indicators (e.g., TIMMS and PISA) have showed that students from the United States did not perform well in mathematics and science compared to other developed countries (e.g., Singapore, and China), thus putting their scientific leadership and economic power in danger. The second reason why the United States is concerned about K-12 STEM education is due to the size of the mathematics and science achievement gaps between students who come from the traditional upper class and those students who come from diverse ethnic and low-SES backgrounds. For example, 
Hispanic students performed far lower than the mean in mathematics and science on the national examinations (Hill, Bloom, Black, \& Lipsey, 2008).

One of the goals for STEM education reported by National Research Council (2011) was to increase the number of underrepresented students who pursue STEM majors in their post-secondary education in order to fill an increased portion of prominent STEM-related job needs in the United States. Educate and Innovate (2009) was developed to address the achievement gap issue and aims to increase underserved students' interest in mathematics and science during the K-12 education years (Executive Office of the President, 2009). Young (2005) showed that despite the increasing number of underrepresented students entering post-secondary education, these students have been underrepresented in pursuing STEM majors. Later, the National Science Board (2010) reported that although non-White and non-Asian groups represent one quarter of the entire U.S. population, only 10 percent of all STEM related doctorates are awarded to these groups. Quickly changing demographic patterns in the United States require that non-White and non-Asian students pursue STEM related careers to fill an increasing portion of prominent STEM positions in the United States.

Although there is an effort to increase the number of students who pursue advanced STEM degrees, increasing the number of students who pursue the STEM related workforce (e. g., K-12 STEM teachers, computer and medical assistance, and nursing) is equally important for the nation's economic competitiveness in the global market (U.S. Department of Labor, 2007). Lacey and Wright (2009) noted that these jobs do not require advanced STEM degrees. Having a vocational certification with a 
STEM related major or a bachelor's degree in a STEM associated field is sufficient. Not surprisingly, the second goal for K-12 STEM education reported by the NRC (2011) is to "Expand the STEM-capable workforce and broaden the participation of women and minorities in that workforce" (NRC, 2011, p. 5). This goal was important because the domestic needs for a workforce in STEM-associated fields increased rapidly from 2008 to 2009. The National Science Foundation (2010) reported that while the unemployment rate from 2008 to 2009 increased 3.8\%, the needs of the workforce in STEM-associated jobs increased by $3.3 \%$. In the next decade, it is projected that there will be 20 new occupations, and $80 \%$ of these occupations will be related to STEM fields. While $5 \%$ of these occupations will require an advanced STEM degree, $75 \%$ of them will require solely vocational certification or an undergraduate degree with a major in a STEM associated field (Lacey \& Wright, 2009). In order to fill a rapidly increasing portion of the STEM workforce, more and more K-12 STEM students need to pursue STEM related majors in their post-secondary education and later follow STEM related career pathways. The NRC (2011) noted that achieving this goal is essential because "the nation's economic future depends on preparing more K-12 students to enter these fields" (p. 5).

The Educate and Innovate program's central aim is to increase STEM literacy in K-12 education regardless of students' future career plans. NRC (2011) also reported the last and most important goal for STEM education is to increase STEM literacy, which is a key $21^{\text {st }}$ century skill, for all students even if they do not pursue a STEM-related career pathway. The goal is to provide students with the necessary knowledge and 
understanding of basic scientific and mathematical concepts that they face in real life (NRC, 1996). Achieving this goal is vital because current employers in various industries have complained of their employees' lack of mathematics, technology, and problem-solving skills (National Governors Association, 2007). Increasing STEM literacy for all students, not just for those who follow STEM-related career pathways in their postsecondary education, will make future citizens capable of dealing with the complex problems of the $21^{\text {st }}$ century's scientific and technology-driven society (NRC, 2011).

\section{Statement of Purpose}

Achieving all three goals mentioned above for the nation's K-12 STEM education is possible by incorporating STEM for all students. Beiber (2008) noted that students' school experiences were positively correlated with their science and mathematics course selection, achievement, and persistence in these fields. Therefore, it is predicted that participation in STEM schools may increase students' science and mathematics achievement because these schools do the following: a) emphasize the importance of STEM disciplines, b) target underserved populations, c) implement rigorous science and mathematics curriculum, d) have more STEM instructional time, e) provide more resources for STEM teaching and learning activities, and f) hire quality science and mathematics teachers (NRC, 2011). Figure 1 shows the conceptual framework for the present study. 


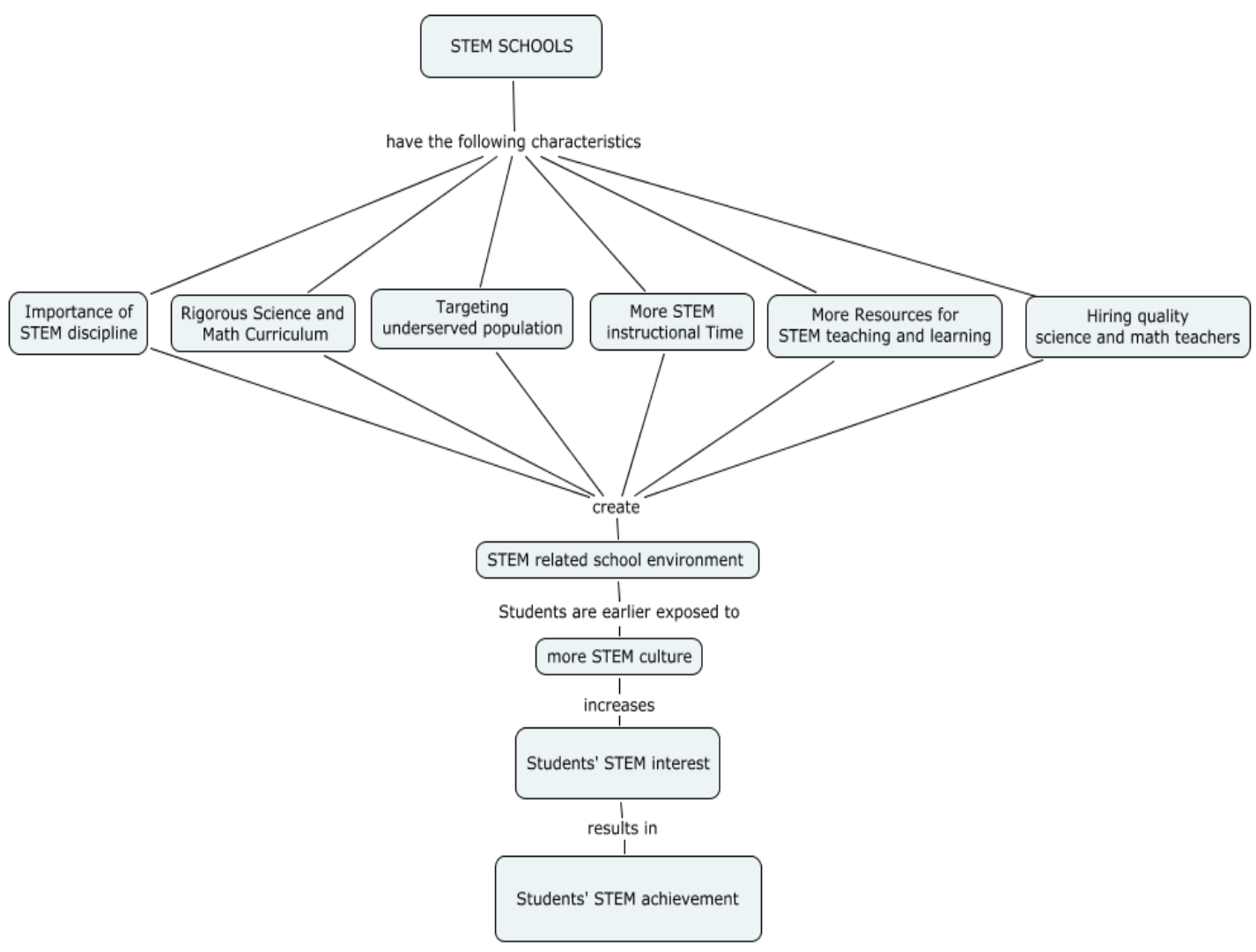

Figure 1. Conceptual Framework for the Present Study 


\section{STEM Schools}

STEM schools are designed to decrease the mathematics and science achievement gaps among various ethnic groups and to increase all K-12 students' mathematics and science scores on both national and international standardized tests. There are three types of STEM schools: selective STEM schools, inclusive STEM schools, and schools with STEM-focused career and technical education (CTE). Selective and inclusive STEM schools are the two most common STEM schools across the Unites States (NRC, 2011). The curriculum for the selective and inclusive STEM schools was designed to improve students' science and mathematics learning by engaging students with hands-on tasks in a collaborative and competitive environment (Gonzalez \& Kuenzi, 2012). There are some differences between these two types of STEM schools in terms of their organization. The clearest distinction between selective STEM schools and inclusive STEM schools is the admission criteria. With regard to admission criteria, selective STEM schools admit only talented and motivated students to STEM related fields while inclusive STEM schools have no selective admission criteria. Because of the disparity among admission criteria between the two STEMschool types, inclusive STEM schools are considered to serve a broader population (NRC, 2011). Young, House, Wang, Singleton, and Klopfenstein (2011) noted that "Inclusive STEM schools are predicated on the dual promises that math and science competencies can be developed, and students from traditionally underrepresented populations need access to opportunity to develop these competencies to become full participants in areas of economic growth and prosperity" (p. 2). Therefore, inclusive 
STEM schools have a unique structure to achieve the three goals stated by NRC (2011) for K-12 STEM education. In the present study, we only included inclusive STEM schools, which will be compared with non-STEM schools.

In the present study, we chose inclusive STEM schools in the state of Texas because Texas has one of the biggest STEM initiatives. The first six T-STEM academies started serving students in 2006, and the number of T-STEM academies has persistently expanded from 2006 to 2014. Currently, there are 65 T-STEM academies (26 campuses for only high school students and 39 campuses for both middle and high school students) serving about 35,000 students in Texas. Therefore, selecting inclusive STEM schools in Texas provides us a large data set and makes sure we have reasonable time to observe changes on students' science and mathematics achievement after schools turned into STEM schools.

The other two reasons why inclusive STEM schools in Texas were selected is for the two characteristics of inclusive STEM schools in Texas. One important characteristic of T-STEM academies is the "blueprint" that guides schools in the planning and implementation of innovative instructional methods. The blueprint specifies that all TSTEM schools are inclusive, and cannot be selective at the time of enrollment. In addition, the blueprint specifies that each T-STEM academy needs to have at least $50 \%$ of students who are economically disadvantaged and at least $50 \%$ of students who come from traditionally underrepresented subpopulations (Young et al., 2011). A second important characteristic of inclusive STEM schools in Texas is T-STEM centers. TSTEM academies were divided into parts based on their regions, and each region 
incorporated a T-STEM center. The T-STEM centers' aim is to help T-STEM academies by creating innovative STEM instructional materials and providing effective professional development to teachers. There are seven T-STEM centers, and these support more than 2,800 STEM teachers to empower their teaching in STEM-related subjects (Texas Education Agency, 2013). Besides creating innovative science and mathematics classrooms and delivering professional development to teachers, these educational centers are charged with a) designing innovative STEM curricula; and b) creating partnerships among businesses, universities, and school districts. T-STEM academies, along with professional development centers and networks, work collaboratively to improve the quality of instruction and students' academic performance in STEM-related subjects at secondary schools. T-STEM academies are also well equipped with labs that allow teachers to adopt innovative instructional methods in science and mathematics classrooms.

\section{Research Questions}

1) How do students who participated in T-STEM schools perform on TAKS mathematics compared to their corresponding peers who participated in traditional public schools in Texas?

2) Controlling for students' demographics (gender, ethnicity, and SES), what is the effect of school types (STEM schools and non-STEM schools) on students' mathematics achievement? 


\section{Methodology}

In this quantitative research project, student and school-level data about students who participated in inclusive T-STEM high schools, as well as matched students who participated in non-T-STEM high schools, were obtained from the Texas Education Agency (TEA) website. This statewide analysis was based upon 36 schools, of which 18 were T-STEM and 18 were matched non-STEM schools. In this study, only 18 T-STEM academies of 65 T-STEM academies were selected because the selected schools needed to have the criterion of being turned into inclusive STEM schools before or during the 2008-2009 academic year. Thus, the present study included only students who participated in STEM academies for at least three years.

In order to match students who participated in $18 \mathrm{~T}$-STEM academies with their corresponding peers who participated in 18 non-STEM schools, school-level data was first matched by following the TEA campus comparison method. This comparison is based upon the following school-level variables: 1 ) ethnicity ( $\%$ of Hispanic students, $\%$ of African American students, and \% of White students), 2) economic disadvantage status (free lunch, reduced price lunch, other public assistance, and none), 3) English language proficiency (met with English language proficiency state standard, and not met with English Language proficiency standard), and 4) school mobility rate.

The sample consisted of 1,887 students (940 from T-STEM schools and 947 from non-STEM schools) who received a TAKS mathematics score in 2011. Students were excluded from the study if they did not have a TAKS mathematics score in 2011. Students' $11^{\text {th }}$ grade mathematics TAKS scale scores were used as an outcome of 
students' mathematics achievement. Students' gender, ethnicity, and SES background were added as predictors to the model in order to determine the promising effects of STEM schools.

\section{Procedures for Analysis}

This study used hierarchical linear modeling (HLM) techniques to construct a two-level model for analysis. This technique allows the simultaneous estimation of between-schools variables (STEM schools and non-STEM schools), and within-school level variables (students' mathematics TAKS scale scores, ethnicity, gender, and SES). Kreft, DeLeuw, and Van Der Leeden (1994) noted that HLM software provides the same results as other commonly used software (e.g. SAS, and ML4), and is perfectly appropriate for disentangling multilevel effects. A series of model finesses were estimated by using HLM software, and this procedure resulted in the best model with specific student and school-level variables. Based on a theoretical and empirical consideration reported by NRC (2011), each student-level variable was added one at a time to the model and evaluated for statistical significance. The same procedure was followed for the school-level predictor, and its effects were also evaluated for statistical significance. The slopes of student-and school-level variables were "fixed" and not allowed to randomly vary if random effects of these variables were not statistically significant in improving the model fitness. The indices of model fitness were based on a Chi-square test, in which deviations' scores and degrees of freedom $(d f)$ provided by HLM software were subtracted from each other to determine whether the slope of the variables had random or fixed effects. 


\section{Results}

\section{Model Specification}

Using the variables discussed in the NRC (2011) report, student and school-level data were added to the model in order to test whether STEM schools increase students' mathematics achievement in comparison to students' mathematics achievement in nonSTEM schools. Students were treated as Level 1 and schools as Level 2, indicating that this study investigated school types (STEM schools and non-STEM schools) that may be associated with average mathematics achievement of students. This study also examined how students' demographics associated with students' mathematics achievement may vary from STEM schools to non-STEM schools. Once the slope of each variable was decided to be fixed or random, the best model (see in table 2) was drawn. 
Table 2

Model Summary

$$
\begin{array}{ll}
\hline \text { Level } & \text { Model } \\
\hline \text { Level1 } & \text { MATH. } 2_{i j}=\beta_{0 j}+\beta_{1 j}^{*}\left(H_{i j}\right)+\beta_{2 j}^{*}\left(B_{i j}\right)+\beta_{3 j} *\left(A_{i j}\right)+\beta_{4 j} *\left(F E M A L E_{i j}\right)+ \\
& \beta_{5 j} *\left(S E S_{i j}\right)+r_{i j} \\
\text { Level2 } & \beta_{0 j}=\gamma_{00}+\gamma_{01} *\left(S T E M 9 \_M E_{j}\right), \beta_{1 j}=\gamma_{10}+\gamma_{11} *\left(S T E M 9 \_M E_{j}\right), \beta_{2 j}=\gamma_{20}+ \\
& \gamma_{21} *\left(S T E M 9_{-} M E_{j}\right), \beta_{3 j}=\gamma_{30}+\gamma_{31} *\left(S T E M 9_{-} M E_{j}\right), \beta_{4 j}=\gamma_{40}+ \\
& \gamma_{41} *\left(S T E M 9 \_M E_{j}\right), \beta_{5 j}=\gamma_{50}+\gamma_{51} *\left(S T E M 9 \_M E_{j}\right)
\end{array}
$$

In the study, all independent variables were categorical variables. A dummy coding strategy was necessitated to use these independent variables in HLM software. In this procedure, males were taken as the reference group for gender; Whites were the reference group for ethnicity, high-SES background of students was the reference for SES, and, non-STEM schools were specified as the reference group for schools.

Therefore, the baseline reference group in the present study comprises students who are White, male, and from a high-SES background in non-STEM schools. This group was selected as the reference group because this group traditionally is considered to be upper class, and the previous studies already showed the existing mathematics achievement gap between students who come from underrepresented groups and students who come from the upper class (Bicer, Capraro, \& Capraro, 2013). In table 3, the intercept $\left(\gamma_{00}\right)$ is 
estimated as $2356.4(S E=9.6) \mathrm{p}<0.01$, which is the predicted mean mathematics score for students who are in the reference group in the $11^{\text {th }}$ grade. The predicted mean differences of mathematics scores between STEM and non-STEM schools for students who are white, male, and high-SES is $\left(\gamma_{01}=31.39,(S E=23)\right)$, but the predicted mathematics scores of these two groups were not statistically significantly different from each other at $p>.05$.

Table 3

Final Estimation of Fixed Effects

\begin{tabular}{lrrrrr}
\hline Fixed Effect & Coefficient & \multicolumn{1}{c}{$S D$} & \multicolumn{1}{c}{$t$-ratio } & $N$ & $p$-value \\
\hline For INTRCPT1, $\beta_{0}$ & & & & & \\
$\quad$ INTRCPT2, $\gamma_{00}$ & 2356.39 & 9.60 & 245.30 & 1887 & $<0.001$ \\
$\quad$ STEM, $\gamma_{01}$ & 31.38 & 23.55 & 1.33 & 1887 & 0.183 \\
\hline For Hispanic slope, $\beta_{1}$ & & & & & \\
$\quad$ INTRCPT2, $\gamma_{10}$ & -93.74 & 12.71 & -7.37 & 1887 & $<0.001$ \\
$\quad$ STEM, $\gamma_{11}$ & 56.01 & 28.07 & 1.99 & 1887 & 0.046 \\
\hline For Black slope, $\beta_{2}$ & & & & & \\
$\quad$ INTRCPT2, $\gamma_{20}$ & -155.71 & 25.04 & -6.21 & 1887 & $<0.001$ \\
$\quad$ STEM, $\gamma_{21}$ & 29.20 & 39.91 & 0.73 & 1887 & 0.465 \\
\hline For Asian slope, $\beta_{3}$ & & & & & \\
INTRCPT2, $\gamma_{30}$ & -130.37 & 153.53 & -0.84 & 1887 & 0.396 \\
$\quad$ STEM, $\gamma_{31}$ & 184.12 & 164.35 & 1.12 & 1887 & 0.263 \\
\hline For FEMALE slope, $\beta_{4}$ & & & & & \\
INTRCPT2, $\gamma_{40}$ & -10.32 & 8.23 & -1.25 & 1887 & 0.210 \\
$\quad$ STEM, $\gamma_{41}$ & -13.54 & 16.02 & -0.84 & 1887 & 0.398 \\
\hline For SES slope, $\beta_{5}$ & & & & & \\
$\quad$ INTRCPT2, $\gamma_{50}$ & -16.02 & 11.58 & -1.38 & 1887 & 0.167 \\
$\quad$ STEM9, $\gamma_{51}$ & 4.613 & 20.75 & 0.22 & 1887 & 0.824 \\
\hline
\end{tabular}


Participation in STEM schools by students who come from a minority ethnic background (Asian, Black, and Hispanic) showed positive effects on students' overall mathematics scores, but the only statistically significant interaction effect of 'ETHNICITY' and 'STEM' is for Hispanic students with $\left(\gamma_{11}=56.02,(S E=28.07), \mathrm{p}<\right.$ .05). This means that participating in STEM schools statistically significantly increased Hispanic students' mathematics scores relative to the reference group's predicted mean mathematics score. Hispanic students in STEM schools performed 181.16 units predicted mean score higher than Hispanic students in non-STEM schools. The interaction effect of participating in STEM academies and gender was negative for female students, but this interaction effect was not statistically significant. This interaction was formed by multiplying the scores for the variables 'STEM" and "FEMALE" with the negative value $\left(\gamma_{11}=-13.54\right)$, meaning that male students' predicted mathematics score tends to increase more in comparison to female students' mean mathematics score as they participate in STEM schools. Comparing female students' predicted mean mathematics score in terms of their school types yielded that female students who participated in STEM schools performed 31 units higher on the $11^{\text {th }}$ grade TAKS standardized mathematics test than female students who participated in nonSTEM schools. For students who come from a low-SES background, the interaction effect of participation in STEM schools and SES background on students' predicted mean mathematics score was positive $\left(\gamma_{51}=4.61,(S E=20.75)\right)$, but not significant $(p>$ .05). This interaction means that students who come from lower SES backgrounds and participate in STEM schools tend to increase their mathematics score more in 
comparison to students who come from higher SES backgrounds and participate in STEM schools. Comparing high and low-SES background students' mathematics scores in terms of the students' school types revealed that students who come from a low-SES background and participate in STEM schools performed 52 units higher on their math score than students who come from low-SES background and participate in non-STEM schools.

\section{Conclusion}

The purpose of the present study is to examine how students' performance on TAKS mathematics differs in terms of their school type as STEM and non-STEM schools. Comparing students' mathematics TAKS performance in grades 9 and 10 in terms of their school types has been already; however, no study has investigated how students' TAKS mathematics performance differs in terms of students' school type (i.e. STEM and non-STEM) when students were in grade 11. This is one of but not the main reason why the present study focuses on only $11^{\text {th }}$ grade students. The main aim of focusing on $11^{\text {th }}$ grade is to see the effect of participating in T-STEM schools on students' mathematics achievement after they completed $9^{\text {th }}, 10^{\text {th }}$, and $11^{\text {th }}$ grades in TSTEM schools compared to their corresponding peers' mathematics achievement in nonSTEM schools.

Previous research's findings revealed that $9^{\text {th }}$ graders in T-STEM academies performed slightly better in mathematics than their matched peers in non-STEM schools. Likewise, $10^{\text {th }}$ graders in T-STEM academies performed better in mathematics than their counterparts in comparison schools. Although there was a difference in students' 
mathematics performance favoring T-STEM academies, the effect sizes ranged from 0.12 and 0.17 (Young et al., 2011). The present study did not find a statistically significant difference in students' TAKS mathematics scores between T-STEM and matched non-STEM schools when controlling for ethnicity, gender, and SES. This can be explained by the selection of the reference group and T-STEM schools' profiles. In the present study, the reference baseline group was selected as White, male, high-SES background students in non-STEM schools. As reported in the T-STEM blueprint, at least $50 \%$ of students in T-STEM academies need to come from the underserved population and/or $50 \%$ need to be economically disadvantaged (Young et al., 2011). Students who are academically successful and come from the upper class may not be eager to participate in T-STEM academies due to the diverse profile of T-STEM schools.

The most important and interesting finding of this study is the interaction effect of 'STEM' and 'Hispanic, which is statistically significant $(p<0.05)$. This means that participating STEM schools statistically significantly increase Hispanic students' mathematics score relative to the reference group's predicted mean mathematics score. This finding is consistent with prior work by Crisp, Nora, and Taggart (2009), which showed that being Hispanic was not found to decrease the chance of a student's success in STEM compared to White students. Controlling for gender and SES in the present study, results show being Hispanic in STEM schools increases the chance of success in mathematics; however, being Hispanic in non-STEM schools decreases the chance of success in mathematics controlling for gender and SES. This conclusion confirms the finding that Hispanic students increased their scores on high-stakes test when they 
participated in T-STEM academies (Gourgey, Asiabanpur, Crawford, Grassso, \& Herbert, 2009). These findings might be explained by the school factors (Gainen, 1995) that may influence students' mathematics achievement. The first factor is the highly competitive classroom environment in non-STEM schools that may discourage Hispanic students from being successful and represented in mathematics. Because T-STEM academies need to have at least $50 \%$ of their students from traditionally underrepresented subpopulations, Hispanic students may have more opportunity to be represented in mathematics classrooms compared to their Hispanic peers in non-STEM schools. The second factor is a lack of engaging teaching and learning practices that promote students' active participation, which is also related to the first factor (Gainen, 1995). Teachers in T-STEM academies are encouraged to implement innovative teaching and learning methods in mathematics classrooms. These practices include but are not limited to project-based learning, problem-based learning, and inquiry based learning. These practices enable students to become actively involved in their learning process. Hurtado et al. (2006) indicated that Hispanic students are more likely to be successful in mathematics when they participate in a student-centered classroom rather than a traditional classroom. This might be explained by interaction opportunities that arise in student-centered classrooms. Because T-STEM schools need to have at least $50 \%$ of their students from underrepresented subpopulations, Hispanic students may not feel themselves a minority group in T-STEM schools (Cole \& Espinoza, 2008). Thus, they may interact more with their teachers and friends in a student-centered classroom environment because they may feel more comfortable than they do in school and 
classroom settings in which they are considered as minorities. Cole and Espinoza (2008) found that Hispanic students performed better in mathematics when they had cultural congruity in their schools. Active engagement in a collaborative environment might be better for Hispanic students than silent listening in a traditional classroom.

The finding that Hispanic students' mathematics achievement in STEM schools is higher than Hispanic students' mathematics achievement in non-STEM schools, controlling for gender and SES, is important because decreasing the mathematics achievement gap between students who come from the traditional upper class and students who come from underrepresented subpopulations is essential to increasing the number of STEM majored people in order to maintain the United States' scientific leadership (NRC, 2011). By the end of 2050, the number of Hispanic students aged between 5 and 17 will be more than 20 million (Chapa \& De La Rosa, 2006). This rapid change in demographics also emphasizes how Hispanic students' successes in mathematics play an essential role in the United States' future scientific leadership and economic power. The present study suggests that the number of STEM schools needs to be extended especially in high Hispanic-population areas. This may help Hispanic students increase their interest in mathematics and other STEM related fields. Therefore T-STEM schools may achieve the NRC's goal of decreasing the achievement gap between students who come from underrepresented subpopulations and students who come from the traditional upper class. 


\section{CHAPTER III}

\section{STEM SCHOOLS VS. NON-STEM SCHOOLS: COMPARING STUDENTS' \\ MATHEMATICS GROWTH RATE ON HIGH-STAKES TEST}

PERFORMANCE*

\section{Introduction}

STEM education refers to teaching and learning in the disciplines of science, technology, engineering, and mathematics. Quality STEM education is critical for a country to be scientifically and technologically relevant. The two foremost reasons why STEM education in K-12 is critical are that today's world requires every individual to understand scientific and technological knowledge (National Research Council [NRC], 2011; Young, House, Wang, Singleton, \& Klopfestein, 2011) and that successes in STEM disciplines play a vital role for a country's future in the competitive global market (President's Council of Advisor on Science and Technology, 2010). Several reports, including those by the National Academy of Science, National Academy of Engineering, and Institute of Medicine (2011a), have already linked the importance of K-12 STEM education to the ability of the United States to maintain its current scientific leadership and economic power. President Barack Obama, in response to this fact, has launched the Educate and Innovate program to cultivate STEM literacy in K-12

\footnotetext{
* Reprinted with permission from "STEM school vs. non-STEM schools: STEM SCHOOLS VS. NON-STEM SCHOOLS: Comparing Students' Mathematics Growth Rate on High Stakes Test Performance" by Ali Bicer, Bilgin Navruz, Robert M. Capraro, Mary M. Capraro, Tugba A. Oner, \& Peter Boedeker, 2015. International Journal on New Trends in Education and Their Implications, 6(1), 138-150, Copyright [2015] by International Journal on New Trends in Education and Their Implications.
} 
education and increase student interest in STEM related majors. The program focuses on K-12 education because those years are vitally important in developing students' interest in one of the STEM-related subjects (Buxton, 2001). Increasing K-12 students' interest in STEM-related disciplines is essential for encouraging more students to pursue STEM

career pathways in postsecondary education settings. It is imperative that these formative years emphasize STEM success for the entire student population. To achieve this, the United States needs STEM schools that all students can attend regardless of their academic and social background (Bicer, Navruz, Capraro, \& Capraro, 2014; Han, Capraro, \& Capraro, 2014). This led to the development of specialized STEM school initiatives (Navruz, Erdogan, Bicer, Capraro, \& Capraro, 2014; Thomos \& Williams, 2009), which have already showed promising effects in increasing students' science and mathematics achievement (Capraro, Capraro, Morgan, Scheurich, Jones, Huggins, Corlu, \& Younes, 2014; Young et al., 2011).

\section{Concerns \& Goals for STEM education}

The National Assessment of Educational Progress (NAEP) showed that U.S. students were not proficient in mathematics and science (Schmidt, 2011). Additionally, international indicators (e.g., TIMMS and PISA) have showed that students from the United States did not perform well in mathematics and science compared to students in other developed countries (e.g., Singapore), thus putting U.S. scientific leadership and economic power in danger. This result is one of the main reasons why the U.S. is concerned about STEM education in K-12 and why the first goal is to increase all students' success in STEM related disciplines. 
Another concern is the size of the mathematics and science achievement gaps between students who come from a traditionally upper class background and those students who come from diverse ethnic and low socioeconomic status (SES) backgrounds. This achievement gap puts young people at a disadvantage when seeking employment because many of the high paying jobs require a high level of STEM related proficiency. Additionally, the domestic need for a workforce in STEM associated fields increased rapidly from 2008 to 2009 , indicating that there are positions available for those who qualify. Thus, the second goal for K-12 STEM education is to "Expand the STEM-capable workforce and broaden the participation of women and minorities in that workforce" (NRC, 2011, p. 5). Achieving this goal would increase the available workforce for a rapidly expanding job market.

The National Science Foundation (2010) reported that while the unemployment rate from 2008 to 2009 increased 3.8\%, the needs of the workforce in STEM associated jobs increased by $3.3 \%$. In the next decade, it is projected that there will be 20 new occupations, of which $80 \%$ will be related to STEM fields. While $5 \%$ of these occupations will require an advanced STEM degree, $75 \%$ of them will require solely vocational certification or an undergraduate degree with a major in a STEM associated field (Lacey \& Wright, 2009). In order to fill the rapidly increasing STEM workforce, more and more K-12 STEM students need to pursue STEM related majors in their postsecondary education and later follow STEM-related career pathways.

The last concern is the $21^{\text {st }}$ century's increasing scientific and technological demands that require every individual to know basic science and mathematics. In the 
past, science and mathematics were considered the disciplines for talented people (Stotts, 2011), but today's world requires each individual to know basic scientific, mathematical, and technological knowledge. Thus, the last and most important goal for STEM education, increasing STEM literacy for all students regardless of whether they pursue a STEM related career pathway, is vital (NRC, 2011). Achieving this goal is strategically important because current employers in various industries have complained of their employees' lack of mathematics, technology, and problem-solving skills. Increasing STEM literacy for all students, not just those who follow STEM-related career pathways in their postsecondary education, will make future citizens capable of dealing with the complex problems of a scientifically and technologically driven $21^{\text {st }}$ century society (NRC, 2011).

\section{STEM Schools}

STEM schools are designed to decrease the mathematics and science achievement gaps among various ethnic groups and to increase all K-12 students' mathematics and science scores on both national and international standardized tests (Bicer, Navruz, Capraro, \& Capraro, 2014; Capraro, Capraro, \& Lewis 2013; Capraro, Capraro, \& Morgan, 2013). There are three types of STEM schools: selective STEM schools, inclusive (i.e., open-admission) STEM schools, and schools with STEMfocused career and technical education (CTE). Selective and inclusive STEM schools are the two most common STEM schools across the Unites States (NRC, 2011). The curriculum for selective and inclusive STEM schools was designed to improve students' science and mathematics learning by engaging students with hands-on tasks in a 
collaborative and competitive environment (Gonzalez \& Kuenzi, 2012). There are some differences between these two types of STEM schools in terms of their organization. The clearest distinction between selective STEM schools and inclusive STEM schools is the admission criteria. Selective STEM schools admit only students who are talented in and motivated toward STEM related fields while inclusive STEM schools have no selective admission criteria. Because of the difference between admission criteria of the two STEM school types, inclusive STEM schools are considered to serve a broader population (NRC, 2011). Young, House, Wang, Singleton and Klopfenstein (2011) noted that "Inclusive STEM schools are predicated on the dual promises that math and science competencies can be developed, and students from traditionally underrepresented populations need access to opportunities to develop these competencies to become full participants in areas of economic growth and prosperity" (p. 2). Therefore, inclusive STEM schools utilize a unique school structure to achieve the three goals stated by NRC (2011) for K-12 STEM education. In the present study, we only included inclusive STEM schools, which were compared with non-STEM schools.

In this study, STEM schools were selected from the state of Texas because it has one of the biggest inclusive STEM school initiatives in the United States. STEM schools in the state of Texas are known as Texas STEM (T-STEM) academies. T-STEM academies are defined by a unique "blueprint" that differentiates it from non-STEM schools. One important characteristic of the blueprint is the implementation of innovative instructional methods such as project-based learning, inquiry-based Learning, and problem-based learning. T-STEM academies are also well equipped with labs to 
facilitate the adoption and utilization of these innovative instructional methods. The blueprint requires that all T-STEM academies are inclusive and cannot be selective at the time of enrollment. In addition, the blueprint specifies that each T-STEM academy needs to comprise of at least $50 \%$ of students who are economically disadvantaged and at least $50 \%$ of students who come from traditionally underrepresented subpopulations (Young et al., 2011). Six T-STEM academies started serving students in 2006, and the number of T-STEM academies expanded from 2006 to 2014. Currently, there are 65 T-STEM academies ( 26 campuses for only high school students and 39 campuses for both middle and high school students) serving approximately 35,000 students in Texas. T-STEM academies were divided into groups based on their region, and each region is led by a TSTEM center. T-STEM centers have the role of supporting T-STEM academies by creating innovative STEM instructional materials and providing effective professional development to teachers. There are seven T-STEM centers that support more than 2,800 STEM-related teachers by empowering their teaching in STEM related subjects (Texas Education Agency, 2013). Besides creating innovative science and mathematics classrooms and delivering professional development to teachers, these educational centers were charged with a) researching innovative STEM curricula; and b) creating partnerships among businesses, universities, and school districts. T-STEM academies, along with professional development centers and networks, work collaboratively to increase the quality of instruction and students' academic performance in STEM-related subjects at secondary schools. 


\section{T-STEM Academies' Promising Effects}

Researchers conducted both qualitative and quantitative studies to explore the effects of attending T-STEM academies on students' science, reading, social science, and mathematics achievement (Capraro et al. 2013; Gourgey et al., 2009; Stotts, 2011; Young et al., 2011). The qualitative (Gourgey et al., 2009) and quantitative studies (Capraro et al. 2013; Stotts, 2011; Young et al., 2011) regarding T-STEM academies indicated promising effects of T-STEM academies on students' academic achievement. To determine if the positive effects of attending T-STEM academies on students' academic achievement continues, a longitudinal method was used (Capraro et al. 2013; Young et al., 2011). Applying a longitudinal method enables researchers to characterize patterns of change in students' scores over time, which includes both the average trajectory and the variability of each student's trajectory. To compare students' academic achievement in terms of their school types (T-STEM academies and non-STEM schools [traditional public schools]), researchers applied various comparison techniques, such as exact matching or propensity score matching. Results from these studies indicated that students who were in grade 9 in T-STEM academies achieved slightly higher mathematics scores than their peers in the comparison schools. Similarly, results showed that students who were in grade 10 in T-STEM academies received higher mathematics and science scores than their peers in the comparison schools. These findings showed a difference favoring T-STEM academies, but the Cohen's $d$ effect size reported ranged from 0.35 to 2.03 . Results also noted that students who were in grade 9 and attended TSTEM academies were 1.8 times more likely to meet the benchmarks of TAKS reading 
and mathematics than their counterparts in comparison schools. Likewise, students who were in grade 10 and attended T-STEM academies were 1.5 times more likely to meet the benchmarks of TAKS reading, mathematics, social science, and science than their counterparts in comparison schools (Young et al., 2011).

In another attempt to characterize students' academic patterns of change over time in T-STEM academies (Gourney et al., 2009), students who were in grade 10 and participated in T-STEM academies increased their mathematics and reading high-stakes test results compared to their corresponding scores in grade 9 . Students who were in grade 10 and came from low-SES backgrounds increased their mathematics scores compared to their mathematics scores in grade 9. In terms of ethnic background, Hispanic students who were in grade 10 showed the largest increase within any of the ethnic groups in their mathematics scores compared to their mathematics scores in grade 9. Likewise, Bicer (2014) found that attending T-STEM academies statistically significantly increased Hispanic students' mathematics mean score relative to White students' mathematics scores in non-STEM schools. Navruz, Erdogan, Bicer, Capraro, and Capraro (2014) conducted a study to understand how students' TAKS mathematics scores changed after their schools converted to inclusive STEM high schools. Results from this study revealed that students had a statistically significant increase on their mathematics scores after their school adopted and implemented STEM curriculum and instruction. This study also examined the effects of adopting STEM curriculum on females and males. Evidence from this study showed that "both genders experienced practically important changes" (p. 67). 
Researchers mostly focused on students' test scores to compare the success of TSTEM academies compared to matched schools; however, NRC (2011) noted that students' test scores do not tell the whole story of success. In response, researchers also examined the relationship between school types (T-STEM and non-STEM) and dropout rate as a measure of success. Results revealed that students who attended T-STEM academies are 0.8 times less likely to be absent from school than their peers in comparison schools (Young et al., 2011; cf. Capraro et al. 2014). Students who attended T-STEM academies were more comfortable with STEM related disciplines and more likely to pursue a college degree, and more female students took advanced placement (AP) courses (Stotts, 2011). Another important finding revealed that one of the high schools changed its rating from Academically Unacceptable to Academically Acceptable as a result of students' academic achievement scores on high-stakes tests and demographic groups. After schools became T-STEM academies, more students enrolled in college level courses than when their schools were non-STEM schools (Stotts, 2011). The STEM academies were more successful across a wide range of variables including test scores, attitude, truancy, and college matriculation.

The present study applied a longitudinal method to track students' mathematics success between the years of 2009 and 2011. Researchers have already applied a longitudinal method to characterize students' success between the years of 2007 and 2009 (Young et al., 2011). However, these studies were conducted in the earlier stage of newly established T-STEM academies. Therefore, the present study involved only schools that turned into T-STEM academies before the 2008-2009 school years. This 
constraint ensured that the schools had adequate time to implement STEM-specific curriculum and teaching to show promising effects on students' mathematics achievement.

\section{Research Questions}

1) How does initial student mathematics performance differ by school type?

2) What are the mathematical benefits for students who attend T-STEM academies for three years as compared to their non-STEM counterparts?

\section{Methodology}

In this quantitative research project, student and school-level data about students who attended inclusive stand-alone T-STEM academies, as well as matched students who attended non-STEM high schools, were obtained from the Texas Education Agency (TEA) website. This statewide analysis was based upon 36 schools, of which 18 were TSTEM academies and 18 were matched non- STEM (traditional public) schools. In this study, only 18 of the 65 T-STEM academies were selected because of the selection criteria of becoming an inclusive T-STEM school on or before the 2008-2009 school year and because of the designation of the academy whether stand-alone or schoolwithin-school. In stand-alone academies, the entire school is a STEM school, meaning that $100 \%$ of the students attending the school are members of the STEM program. A school-within-school is a different dynamic in which STEM is a program available within a traditional school setting, meaning that not all students that attend the school are necessarily engaged in the STEM program. Thus, the present study included students who attended stand-alone T-STEM academies for at least three years. The sample 
consisted of three years of Texas Assessment of Knowledge and Skills (TAKS) mathematics data for 3,026 students, of whom 1,506 attended 18 T-STEM academies and 1,520 attended 18 non-STEM schools in Texas. The first measurement for the sample was taken when students were at the end of $9^{\text {th }}$ grade in 2009 , and the last measurement for the same students was taken when they were at the end of $11^{\text {th }}$ grade in 2011.

In order to match students who attended 18 T-STEM academies with their corresponding peers who attended 18 non-STEM schools, school-level data was first matched by following the TEA campus comparison method. This comparison is based upon the following school-level variables: 1 ) ethnicity (\% of Hispanic, $\%$ of African American, and \% of White students), 2) economic disadvantaged status (free lunch, reduced price lunch, other public assistance, and none), 3) English language proficiency (ELP) (met the English language proficiency state standard and did not meet the English Language proficiency standard), and 4) school mobility rate (expressed as a ratio of the whole school population to students moving into and out of the school in one year). TSTEM academies and non-T-STEM schools were matched with a 1:1 exact matching strategy using the following: ethnicity, SES, ELP, and school mobility rate.

Students were excluded from the study if they did not have any mathematics TAKS scores in any of the measurement years 2009, 2010, or 2011. Students were also excluded if they: (1) left a T-STEM school and transferred into a non-STEM school, or (2) transferred into a T-STEM school from a non-STEM school. These exclusions 
ensured that the students who attended STEM academies received at least three years of STEM education during their high school years.

In this study, students' mathematics TAKS scale scores were used as an outcome estimate of students' mathematics achievement. A student's mathematics TAKS score at the end of $9^{\text {th }}$ grade was modeled as the estimated initial mathematics achievement plus the change over time, that is, the rate of change, $\left(\pi_{l j k}\right)$, plus error. Additionally, students' gender, ethnicity, and SES background were further added to the model in order to estimate each group's (gender, ethnicity, and SES) initial status and growth rate in mathematics. Further, students' school type was added as the last predictor to the model in order to estimate students' initial status and growth rate in terms of their school types (i.e., STEM or non-STEM).

\section{HLM Analytic Procedures}

Hierarchical linear modeling (HLM) was used to construct a three-level model for analysis. Level-1 was the repeated measures, which were nested within students. Level-2 was the students who were further nested within school types. Level-3 was the school types (STEM and non-STEM). This three-level model was used in the present study to characterize patterns of change in students' measures over time, which included both the average trajectory and the variability of students' trajectories. This technique also allowed the simultaneous estimation of between-schools variables (STEM schools and non-STEM schools), within-school level variables (ethnicity, gender, and SES), and the variances of students' repeated measures. A series of model fit indices were estimated by using HLM software, and this procedure resulted in the best model (see 
Table 4) with specific student and school-level variables. First, students' $9^{\text {th }}$ grade mathematics TAKS scale scores were added as an outcome. Second, based on a theoretical and empirical consideration reported by NRC (2011), each student-level variable (ethnicity, gender, and SES) was added one at a time to the model and evaluated for statistical significance. The same procedure was followed for the school-level predictor, and its effects were also evaluated for statistical significance. The slopes of student-and school-level variables were "fixed" and not allowed to randomly vary if random effects of these variables were not statistically significant in improving the model fitness. The indices of model fitness were based on a Chi-square test, in which deviations' scores and degrees of freedom $(d f)$ provided by HLM software were subtracted from each other to determine whether the slope of the variables had random or fixed effects.

\section{Results}

To examine the differences in mathematics achievement at the end of grade 9 and the growth rate of mathematics achievement from grade 9 to grade 11, a three-level growth model in HLM software was conducted. To address the two research questions, the results section addresses aspects of the questions across two sections: 1) differences in mathematics achievement at the end of grade 9, and 2) differences in growth rate of mathematics achievement from grade 9 to grade 11.

\section{Differences in Mathematics Scores at the end of Grade 9}

The results indicated statistically significant differences in students' mathematics achievement in grade 9 for all independent Level-2 variables. In addition, the interaction 
effects between 'STEM9' and 'Gender' were found statistically significant $(p<0.05)$. Table 1 illustrates $9^{\text {th }}$ graders' mathematics achievement relative to the mathematics achievement of our reference group (White, male, high-SES students in non-STEM schools).

The predicted mean math achievement of our reference baseline group at the end of $9^{\text {th }}$ grade $\left(\gamma_{000}=2265.55\right)$ was statistically significant at $p<0.01$. The difference between T-STEM academies and non-STEM schools $\left(\gamma_{001}=102.13\right)$ was statistically significant $(p<.01)$, which indicates that students in T-STEM academies have higher mathematics scores than students in non-STEM schools at the end of $9^{\text {th }}$ grade controlling for ethnicity, gender, and SES.

We were also concerned about the impact of school types on students' mathematics achievement by students' ethnic background. Results showed that the effect of being Hispanic on students' predicted mean mathematics score relative to White students' predicted mean mathematics score $\left(\gamma_{010}=-96.53\right)$ in non-STEM schools was statistically significant $(p<.001)$. It showed there was a statistically significant difference between Hispanic and White students in non-STEM schools in terms of their predicted mean mathematics score at the end of grade 9 controlling for SES, gender, and school type. In other words, at the end of grade 9, White students' predicted mean 
mathematics TAKS score was higher than Hispanic students' predicted mean mathematics TAKS score in non-STEM schools. Similarly, African American students' predicted mean mathematics score relative to White students' predicated mean score $\left(\gamma_{020}=-173.75\right)$ was also statistically significantly different $(p<0.01)$. In other words, there is a difference between African American students' mathematics achievement and White students' mathematics achievement at the end of grade 9 controlling for gender, and SES. At the end of grade 9, White students achieved higher mathematics scores than African American students' mathematics score in non-STEM schools. 
Table 4

Final Estimation of Fixed Effects for Intercept

\begin{tabular}{llllll}
\hline Fixed Effect & Coefficient & SD & $t$-ratio & $N$ & $p$-value \\
\hline For INTRCPT2, $\beta_{00}$ & & & & & \\
INTRCPT3, $\gamma_{000}$ & 2265.55 & 16.56 & 136.77 & 3026 & $<0.05$ \\
STEM9, $\gamma_{001}$ & 102.13 & 22.54 & 4.53 & 3026 & $<0.05$ \\
\hline For H, $\beta_{01}$ & & & & & \\
INTRCPT3, $\gamma_{010}$ & -96.53 & 14.33 & -6.73 & 3026 & $<0.05$ \\
\hline For B, $\beta_{02}$ & & & & & \\
INTRCPT3, $\gamma_{020}$ & -173.75 & 16.15 & -10.75 & 3026 & $<0.05$ \\
\hline For FEMALE, $\beta_{03}$ & & & & & \\
INTRCPT3, $\gamma_{030}$ & 22.85 & 8.73 & 2.61 & 3026 & $<0.05$ \\
STEM9, $\gamma_{031}$ & -48.23 & 16.62 & -2.90 & 3026 & $<0.05$ \\
\hline For SES, $\beta_{04}$ & & & & & \\
INTRCPT3, $\gamma_{040}$ & -49.57 & 13.98 & -3.54 & 3026 & $<0.05$ \\
STEM9, $\gamma_{041}$ & 31.17 & 15.58 & 2.00 & 3026 & $<0.05$ \\
\hline & & & & & \\
\hline
\end{tabular}

Because females continue to be underrepresented in STEM fields, we were also interested in how the students in T-STEM academies and non-STEM schools compared by gender. The effect for gender on students' predicted mean mathematics score $\left(\gamma_{030}=\right.$ 
22.85) was statistically significant $(p<0.01)$, which indicated that there was a difference between female and male students in grade 9 controlling for ethnicity, SES, and school type. At the end of grade 9, female students achieved higher mathematics scores than did male students in non-STEM schools. Additionally, the interaction effect of 'FEMALE' and 'STEM9' as FEMALE*STEM9 ( $\left.\gamma_{031}=-48.23\right)$ was statistically significant, $p<0.01$, which showed that there was a statistically significant difference between female students in T-STEM academies and male students in T-STEM academies in terms of their mathematics scores at grade 9 controlling for ethnicity and SES. Male students in T-STEM schools achieved higher mathematics scores than female students in T-STEM academies at the end of grade 9, controlling for ethnicity and SES.

When it came to SES, the effect of SES on students' mathematics achievement $\left(\gamma_{040}=-49.57\right)$ was statistically significant $(p<0.01)$, which illustrated that there was a difference between low- and high-SES students on math achievement in grade 9 controlling for gender, ethnicity, and school type. At the end of grade 9, high-SES students in non-STEM schools achieved higher mathematics scores than low-SES students in non-STEM schools, controlling for gender and ethnicity. However, the interaction effect as 'SES*STEM9' $\left(\gamma_{041}=31.18\right)$ was statistically significant $(p<0.05)$. It showed that there was a statistically significant difference between low-SES students in T-STEM academies and high-SES students in T-STEM schools in terms of their mathematics scores in grade 9 controlling for gender and ethnicity. At grade 9, low-SES students in T-STEM academies achieved higher mathematics scores than high-SES students in T-STEM schools, controlling for gender and ethnicity. 


\section{Differences in the Growth Rate of Mathematics Achievement}

Results indicated statistically significant differences in the growth rate of math achievement for all independent Level-2 variables. In addition, the interaction effect of 'STEM9' and 'FEMALE, was found to be statistically significant at $p<.01$. The findings related to the differences in the mathematics scores' growth are represented in Table 5.

The average annual growth rate of mathematics achievement for our reference group (WHITE, male, high-SES students in non-STEM schools) $\left(\gamma_{100}=25.96, p<0.01\right)$ showed an increase of 25.96 points per year. The change per year was statistically significantly different from 0 . In addition, the effect of time*STEM9 $\left(\gamma_{101}=-12.08\right)$ was not statistically significant at $p<0.01$, which showed there was no statistically significant difference found between students in T-STEM academies and non-STEM schools in terms of their growth in mathematics scores when controlling for gender, ethnicity, and SES. Results showed that the growth rate of students' mathematics scores in non-STEM schools was higher than that of students in T-STEM academies controlling for gender, ethnicity, and SES; however, this difference was not statistically significant $(p<.05)$ 
Table 5

Final Estimation of Fixed Effects for Time

\begin{tabular}{|c|c|c|c|c|c|}
\hline Fixed Effect & Coefficient & $S D$ & $t$-ratio & $N$ & $p$-value \\
\hline \multicolumn{6}{|l|}{ For INTRCPT $2, \beta_{10}$} \\
\hline INTRCPT $3, \gamma_{100}$ & 25.96 & 5.04 & 5.14 & 3026 & $<0.001$ \\
\hline STEM9, $\gamma_{101}$ & -12.08 & 11.73 & -1.02 & 3026 & 0.311 \\
\hline \multicolumn{6}{|l|}{ For $\mathrm{H}, \beta_{11}$} \\
\hline INTRCPT3, $\gamma_{110}$ & 10.10 & 3.46 & 2.91 & 3026 & 0.004 \\
\hline \multicolumn{6}{|l|}{ For $\mathrm{B}, \beta_{12}$} \\
\hline INTRCPT3, $\gamma_{120}$ & 20.52 & 3.19 & 6.42 & 3026 & $<0.001$ \\
\hline \multicolumn{6}{|l|}{ For FEMALE, $\beta_{13}$} \\
\hline INTRCPT3, $\gamma_{130}$ & -9.03 & 2.19 & -4.12 & 3026 & $<0.001$ \\
\hline STEM9, $\gamma_{131}$ & 14.84 & 5.45 & 2.72 & 3026 & 0.007 \\
\hline \multicolumn{6}{|l|}{ For SES, $\beta_{14}$} \\
\hline INTRCPT $3, \gamma_{140}$ & 6.57 & 2.57 & 2.55 & 3026 & 0.011 \\
\hline
\end{tabular}

From Table 5, the average annual growth rate of mathematics achievement for Hispanic students in non-STEM schools $\left(\gamma_{120}=10.10\right)$ showed that it increased 10.10 points per year, $p<0.01$. The change per year was statistically significantly different from 0 . The average annual growth rate of mathematics achievement for African 
American students in non-STEM schools $\left(\gamma_{120}=20.52\right)$ increased 20.52 points per year, $p$ $<0.01$. This change per year was also statistically significantly different from 0 .

Controlling for SES, ethnicity, and school type, the average annual growth rate for mathematics achievement for female students in non-STEM schools $\left(\gamma_{130}=-9.03\right)$ showed that the growth rate of mathematics achievement decreased 9.03 per year $(p<$ 0.01) compared to male students in non-STEM schools. The difference per year was statistically significantly different from 0 . This showed that female students' mathematics growth in non-STEM schools was lower than male students' mathematics growth in non-STEM schools. We also have the interaction effect of female*STEM9 $\left(\gamma_{131}=14.84\right)$ that was statistically significant $(p<0.01)$, which indicated that there was a statistically significant difference between female students in T-STEM academies and male students in T-STEM schools in terms of the rate of change in math achievement when controlling for ethnicity and SES. Female students in T-STEM academies had a higher mathematics growth rate than did female students in non-STEM schools. Lastly, the average annual growth rate of mathematics achievement for low-SES students when controlling for gender, ethnicity, and school type $\left(\gamma_{130}=6.57\right)$ was statistically significant $(p<0.01)$, showing that the growth rate of mathematics achievement increased 6.57 per year $(p<0.05)$ in non-STEM schools.

\section{Conclusion}

The objective of the present study is to examine how students who attended TSTEM academies performed on TAKS mathematics in 2009 and how their TAKS mathematics performance changed from 2009 to 2011 compared to that of their 
counterparts in comparison schools. To the best of our knowledge, this study is unique in terms of T-STEM school selection. The present study only included schools that had transitioned to T-STEM academies prior to the 2008-2009 school year. This ensured that students who attended these schools received at least three years of a STEM emphasized education. This criterion also makes sure that schools that turned into T-STEM academies had sufficient time to fully implement STEM teaching and learning practices to show their effects on students' mathematics achievement. Three years is considered sufficient time because NRC (2011) reported that T-STEM academies showed their effects on students' academic achievement in three years.

The study's findings indicated that our reference group's (White, male, high-SES in non-STEM schools) predicted mean TAKS mathematics score was lower than students' predicted mean TAKS mathematics score in T-STEM academies at the end of grade 9. This finding is consistent with prior work by Young et al. (2011), which found that students who attended T-STEM academies performed higher on TAKS mathematics than did their counterparts in comparison schools at grade 9 . This might be explained by the fact that mathematics classrooms in most public-traditional schools focused on either teaching the theoretical background of mathematics or teaching procedural mathematics (Stotts, 2011). Thus, students' mathematics learning in non-STEM schools may become more rote memorization than meaningful learning, and students may have difficulty applying previously learned mathematical facts to new mathematical topics. In order for students to learn mathematics more meaningfully, they need to develop both conceptual and procedural understanding of mathematical facts (Ashlock, 2005), but for some 
students this cannot be achieved without scaffolding. In terms of school types, students' mathematics scores are statistically significantly different in favor of T-STEM academies. T-STEM academies' mathematics instruction might be one potential cause of this achievement difference. From this result, it is possible to deduce that T-STEM academies fulfill their duty, which is to improve students' mathematics and science scores, in terms of mathematics. It might be better for non-STEM schools to adopt STEM learning and teaching practices in mathematics classrooms to increase their students' mathematics learning. STEM practices (i.e., project-based learning [PBL], and problem-based learning) in T-STEM academies' mathematics classrooms give students ownership of their education and provide opportunities to work collaboratively on applicable, hands on activities that are more meaningful than traditional, rote memorization assignments. These instructional methods might be appealing because they simultaneously develop students' conceptual and procedural mathematical understanding.

Another finding revealed that at the end of grade 9, low-SES students in TSTEM academies achieved higher mathematics scores than did students in our reference group. This result might be explained by the possibility that low-SES students who attended T-STEM academies were already interested in STEM related disciplines, which resulted in their decision to attend T-STEM academies. This result may also be explained due to T-STEM academies' obligation to serve underrepresented subpopulations (ethnic minority, female, and low-SES). This obligation provides opportunities to low-SES students who are interested in STEM related disciplines to 
show their potential through enrollment in T-STEM academies. This is important because previous studies reported that the existing mathematics achievement gap between low and high-SES students favored high-SES groups (Bicer, Capraro, \& Capraro, 2013), and another report (NRC, 2011) emphasized that decreasing the mathematics achievement gap between low-and high-SES students is an essential goal for STEM education. By taking into account the fact that low-SES students may enroll in T-STEM academies due to a preexisting interest in STEM disciplines, we can conclude that T-STEM academies' curriculum and teaching features, such as hands-on activities, scaffolding, group work, and real life applications (Avery, Chambliss, Pruiett, \& Stotts, 2010; Young et al., 2011) may help low-SES students achieve their potential in mathematics.

Our findings also indicated differentiation in gender. Male students in T-STEM achieved higher than did females in T-STEM academies at the end of grade 9 controlling for ethnicity and SES. However, female students' mathematics growth rate was statistically significantly higher than male students' mathematics growth rate in T-STEM schools. This might be explained by the fact that female students who attended T-STEM academies may have more positive attitudes towards STEM-related disciplines when presented with opportunities for science and mathematics learning. The curriculum and instruction strategies (group work, active engagement, hands-on activities, real life applications, cooperative and collaborative learning, etc.) in T-STEM academies could have provided a framework for greater engagement (Myers \& Fouts, 1992; Oakes, 1990). This result also could lead us to the conclusion that with proper strategies female 
students' achievement and interest in STEM disciplines could be increased. Increasing female students' achievement and interest in STEM disciplines would lead them to pursue STEM careers, which will close the gap for females in the STEM pipeline (Blickenstaff, 2005) and aid to increase the number of people who are in the STEM workforce. Female students experienced enhanced mathematics performance as indicated by their TAKS mathematics test scores. In terms of ethnicity, it was found that the reference group that included White students had statistically significantly higher mean mathematics scores than did Hispanic and African American students at the end of $9^{\text {th }}$ grade. This shows parallel results with our previous findings (Oner et al., 2014), which showed that African American students' mean mathematics scores were statistically significantly lower than White students among groups of students in TSTEM academies. 


\section{CHAPTER IV}

\section{STEM SCHOOLS VS. NON-STEM SCHOOLS: EXAMINING HISPANIC STUDENTS' MATHEMATICS ACHIEVEMENT}

\section{Introduction}

Traditionally, the purpose of science, technology, engineering, and mathematics (STEM) schools has been to provide advanced STEM coursework to students who are talented and gifted in STEM disciplines (Burton, Lynch, Behrend, \& Means, 2014; Means et al., 2013; Young et al., 2011). Recently, a new and innovative approach to STEM school design known as Inclusive STEM high schools (ISHSs) has emerged. Unlike the original STEM schools known as selective STEM schools, ISHSs accept all students regardless of their previous academic achievement and interest in science and mathematics (Means et al., 2013; NRC, 2011). This new school design for STEM education is one of the suggestions proposed by the NRC (2011), which noted that ISHSs possess great potential for addressing STEM education needs in the United States. STEM education needs are: a) increasing the number of students interested in STEM careers requiring advanced degrees, b) increasing the number of students interested in the STEM workforce requiring vocational skills, and c) increasing the overall science and mathematics literacy of the entire population (NRC, 2011). Achieving these goals is critical to the United States maintaining its current global economic power and scientific leadership (NRC, 2011). 
The focus of the present study is on the ISHS initiative in Texas, with a narrowed focus on the factors influencing underrepresented students' STEM preparation in ISHSs. As a result of the Texas STEM (T-STEM) Initiative, seven T-STEM academies were founded in Texas during the 2006-07 academic year. As of the 2013-14 school year, there were 70 T-STEM academies in Texas serving 40,000 students. There were seven grant-funded T-STEM centers established for the purpose of supporting T-STEM academies. Their mission is to help create innovative instructional models and provide professional development for teachers (Texas Education Agency, 2014). T-STEM academies were designed and implemented under the guidance of a detailed.blueprint that includes: a) providing college preparatory curriculum, b) creating real world relevant instruction, c) establishing a strong academic system, d) offering a wide range of STEM coursework, and e) supporting underrepresented students and preparing them for STEM college programs and careers (NRC, 2011; Young et al., 2011). Support for underrepresented students is a unique attribute of ISHSs and accounts for the primary difference between the two types of STEM schools.

The main purpose of the present study was to discover how Hispanic students' mathematics achievement in ISHSs compared to that of their counterparts in traditional public schools. This study was limited to Hispanic students for the following reasons: 1) Hispanic students in Texas make up the largest population percentage of total enrollment (50.3\%) in 2010-11 (Texas Education Agency [TEA], 2011), and 2) recent research has demonstrated that Hispanic students are the only ethnic group increasing in mathematics achievement by their enrollment in T-STEM academies (Bicer, Navruz, Capraro, \& 
Capraro, 2014). Therefore, the present study's aim was to compare Hispanic students' mathematics performance in terms of their school types (T-STEM academies and nonSTEM schools).

\section{STEM Education}

STEM education refers to the teaching and learning practices in the disciplines of science, technology, engineering, and mathematics. STEM education has come front and center for educators and policymakers in the United States, and many reports have recognized this critical issue. Reports, such as the America Competes Act (2007), Rising above the Gathering Storm (2007), and the President's Council of Advisors in Science and Technology (2010), has suggested earmarking more importance to STEM education in order to ensure the nation's future global economic power and scientific leadership. The reason these reports focused on STEM education was because international indicators such as PISA and TIMSS revealed that American youth fall behind their peers from other developed countries in their scientific and mathematical abilities (Russell, Hancock, \& McCulloguh, 2007). Secretary of Education Arne Duncan (2012) responded to the TIMSS results in a statement saying, "Given the vital role that science, technology, engineering, and math play in stimulating innovation and economic growth, it is particularly troubling...that students in Singapore and Korea are far more likely to perform at advanced levels in science than U.S. students" (Internet). As expected, the National Science Board reported a shortage of STEM workers in the nation's near future (National Science Board, 2010). Later, the National Research Council (2011) stated three goals that need to be achieved in order to maintain the nation's current economic 
power and scientific leadership. First, the number of people who have advanced degrees in STEM majors, such as engineers, doctors, and scientists, needs to be expanded. Second, the number of people who enter the STEM workforce but do not hold advanced STEM degrees needs to be expanded because the majority of STEM careers do not require advanced STEM degrees but require vocational or technical skills. Lastly, the number of people who are able to understand basic science and mathematics concepts needs to increase even if these people do not follow STEM pathways. In all three goals, underrepresented students' STEM matriculation was emphasized due to the rapid change in demographics and the existing STEM achievement gap among students who are from the traditional upper class and students who are underrepresented in STEM majors (Black, Hispanic, female). To achieve these three goals, many interventions were suggested including designing STEM summer camps, offering more advanced science and mathematics classes, and establishing specialized STEM schools. Among the interventions suggested to achieve the three goals for U.S. STEM education, establishing STEM schools was one of the most promising to increase K-12 students' interest in STEM disciplines (NRC, 2011).

There are many types of STEM schools including selective STEM schools, inclusive STEM schools, and STEM-focused career or technical education schools (NRC, 2011). Historically, the most common STEM schools have been selective STEM schools. ISHSs are a relatively new type of STEM school (Burton, Lynch, Behrend, \& Means, 2014). The uniqueness of these schools is that ISHSs "have open enrollment and are focused on underrepresented youth for the successful pursuit of advanced STEM 
studies" (Burton, Lynch, Behrend, \& Means, 2013, p. 64). The mission of inclusive STEM schools provides dual promises that students' science and mathematics achievement can be increased and that those from traditionally underrepresented subpopulations (see Figure 2) can find the opportunities to participate in STEM activities and become potential candidates for STEM related majors (Means, Confrey, House, \& Bhanat, 2008; Scott, 2009; Young et al., 2011).

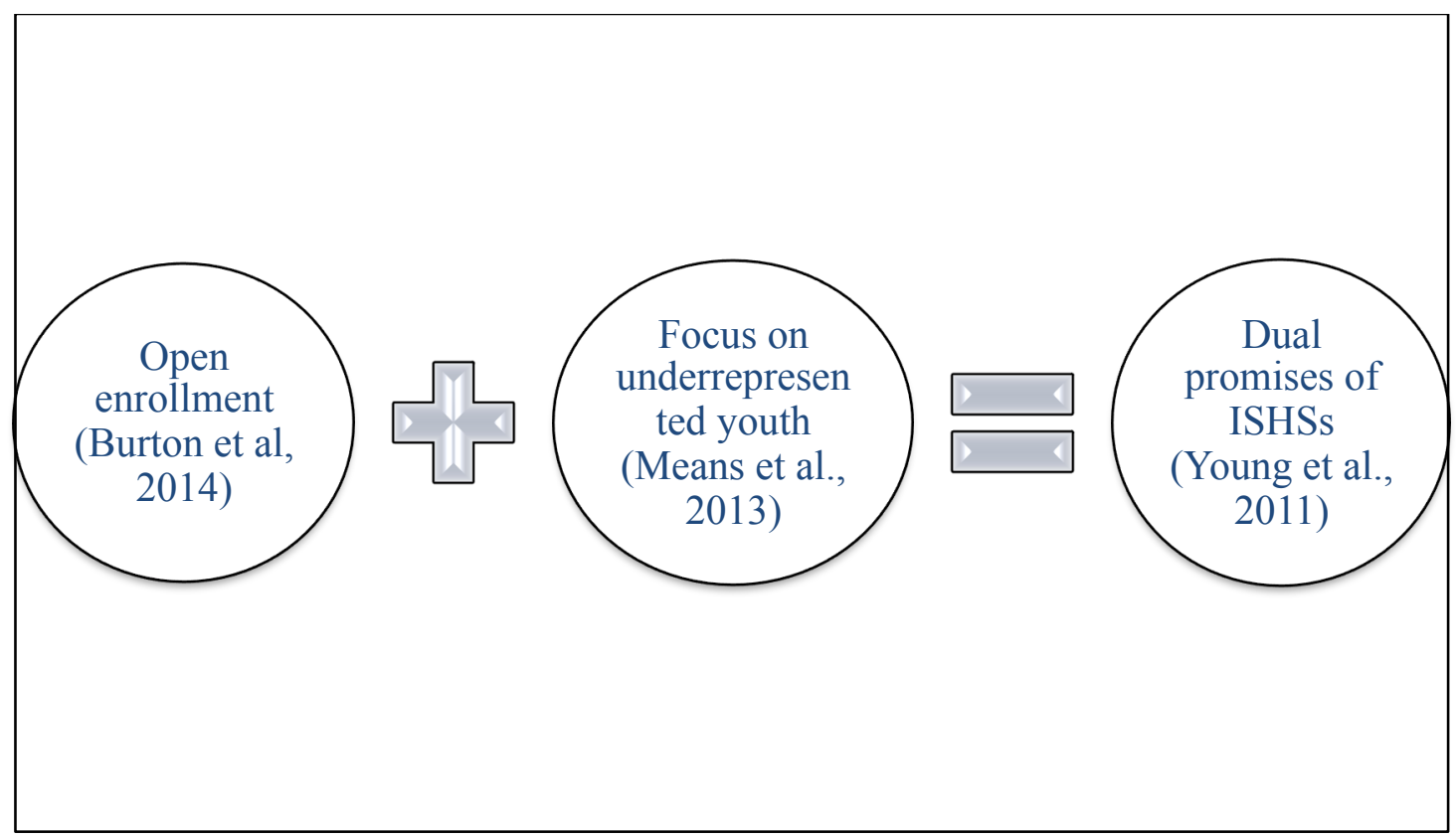

Figure 2. Dual Promises of ISHSs. 
The opportunities structured by ISHSs provide unique approaches to education for students who otherwise would not have access to such stimulating experiences. Roberts (1968) defined opportunity structures as resources available in society that can be used to accomplish an individual's aspirations. ISHSs not only use more resources like advanced technology for creating new learning opportunities, but they also embrace many critical components including, but not limited to, STEM-focused curriculum, innovative instruction techniques (e.g., project based learning [PBL]), informal learning, real world partnerships, early college-level coursework, quality STEM instructors, and support of underrepresented students (Burton et al., 2014). These components of ISHSs together create opportunity structures to encourage underrepresented students' success in STEM disciplines. Failure to provide such components may obstruct students' pathways to success in STEM disciplines.

The elements of successful K-12 STEM programs are: (a) a strong science and mathematics curriculum, (b) appreciation for using STEM in real world applications, (c) modeling success in STEM professions, (d) and access to friends with mutual interest in STEM disciplines (Brody, 2006) (see Figure 3). The first three elements are directly implemented in the curriculum and design of ISHSs while the fourth element is the determining factor in whether or not an ISHS will be successful in achieving its purposes. Young et al. (2011) proposed that in an ISHS, where one of the goals is to increase student motivation and interest in STEM disciplines, students who lack motivation and interest in STEM disciplines would gain these as they progress through the program. This in turn would fulfill the fourth element of successful STEM programs. 


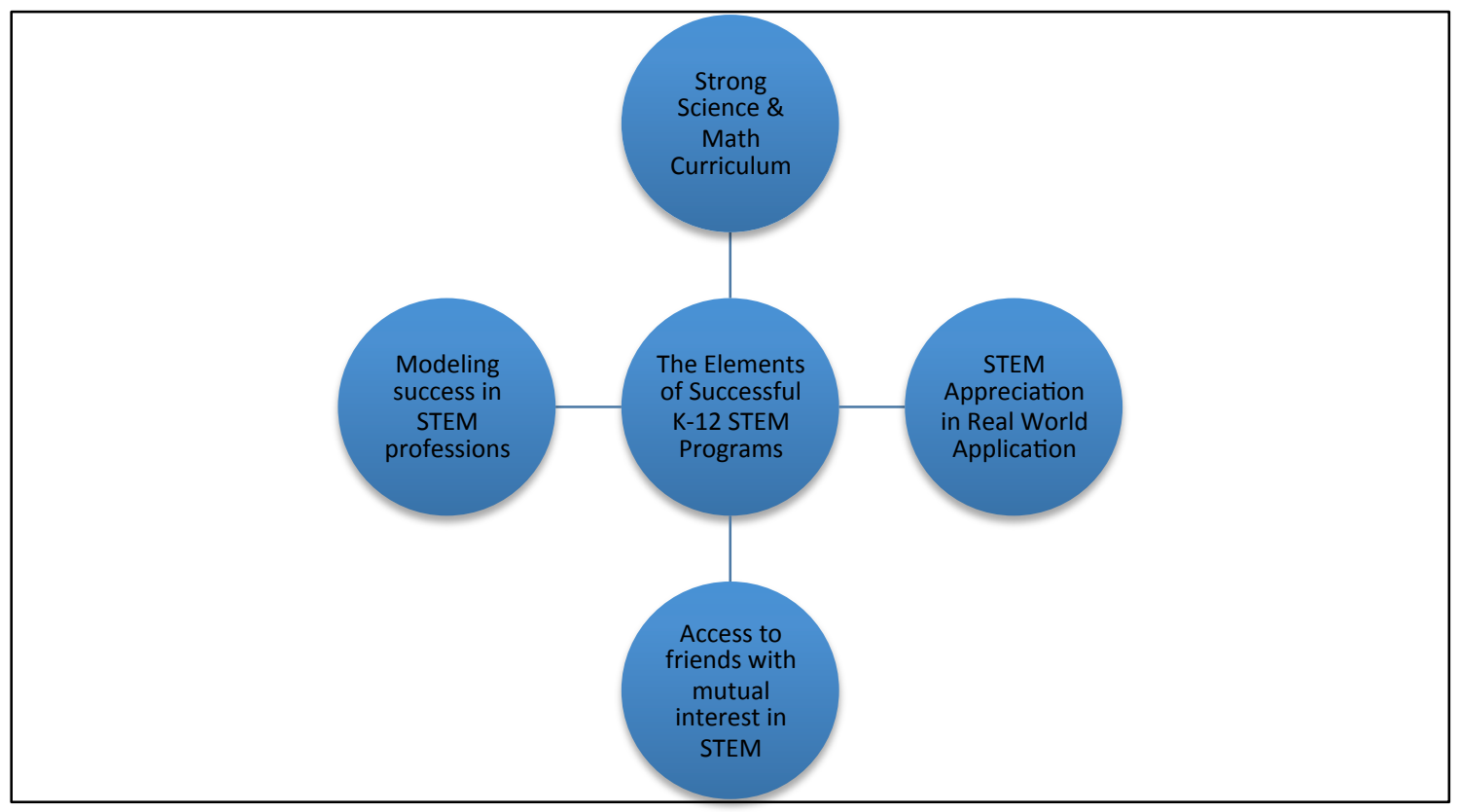

Figure 3. The Elements of Successful K-12 STEM Programs.

ISHSs are important because evidence from previous research showed that K-12 students with interests in mathematics and science are more likely to pursue STEM career pathways when provided with strong curriculum, quality instructors, and studentstudent stimulation (Bloom, 1985; Pyryt, 2000; Subotnik, Tai, Rickoff, \& Almarode, 2010; Subotnik, Duschl, \& Selmon, 1993; Tai, Liu, Maltese, \& Fan, 2006). Because ISHSs emphasize underrepresented students' STEM preparation and offer optimum science and mathematics teaching and learning environments, we hypothesized that underrepresented students who attended STEM high schools perform better than 
underrepresented students enrolled in traditional high schools. In the present study, Hispanic students were selected because data gathered from the state of Texas indicated that Hispanic students are the largest ethnic group in Texas public schools (Castro, 2013). Chapa and De La Rose (2006) noted that the number of Hispanic students in the United States would be more than 20 million by the end of 2050. This rapid change in demographics also demonstrates how Hispanic students' STEM preparation plays a vital role in the United States both in increasing students' overall science and mathematics achievement and in decreasing the mathematics and science achievement gap between students who are underrepresented and students who are traditionally from upper class families.

\section{Texas STEM Initiative}

The T-STEM Initiative offers a fundamental approach to advance studies in STEM disciplines by empowering STEM teachers and inspiring students (Educate Texas, 2014). One of the largest inclusive STEM school initiatives in the U.S. has been developed in Texas (NRC, 2011). This project, the T-STEM Initiative, was launched in 2006 and continues to grow steadily. The objectives of this initiative was to: (a) increase the number of students who follow STEM career pathways; (b) help promote quality school leadership by supporting school redesign efforts, teacher recruitment, and teacher preparation; and (c) assist in the STEM disciplines' long term educational development (Educate Texas, 2014). As of 2014, there were 70 T-STEM academies serving 40,000 students in either grades 6-12 or 9-12. T-STEM academies were separated into seven regions, and each region incorporated a STEM center. These seven T-STEM centers are 
located at universities and regional education service centers and designed to render academic assistance to the T-STEM academies. The T-STEM centers build partnerships with industry and business in order to provide resources for T-STEM academies. More than 2,800 teachers in STEM disciplines receive assistance from these seven T-STEM centers. This assistance includes but is not limited to creating new STEM instructional materials and providing high-quality professional development (Educate Texas, 2014). Avery, Chambliss, Pruiett, and Stotts (2010) noted that the "STEM blueprint" is one of the remarkable characteristics of T-STEM academies that either guides schools in transitioning to becoming T-STEM academies or establishes new T-STEM academies entirely. The blueprint requires that all T-STEM academies have open enrollment and cannot be selective at the time of enrollment. In addition, the blueprint indicates that each T-STEM academy needs to comprise of at least $50 \%$ of students who are economically disadvantaged and/or students who come from traditionally underrepresented subpopulations (i.e., female, diverse, and disabled) (Avery et al., 2010; Young et al., 2011). Because T-STEM academies need to have 50\% of their students from underrepresented subpopulations (Young et al., 2011), and Hispanic students are the largest ethnic group in Texas public high schools, investigating the effects of attending STEM schools on Hispanic students will be most informative. Therefore, the overarching research question is: How does attending T-STEM high schools affect Hispanic students' mathematics achievement growth rate based on Texas Assessment of Knowledge and Skills (TAKS) score results? 


\section{Success of T-STEM Designation}

Empirical research examining whether students in ISHSs do better in mathematics and science than do students in traditional high schools has been sparse (Means et al., 2013; NRC, 2011; Subotnik, Tai, Rickoff, \& Almorode, 2010). This is to be expected, though, given that ISHSs are relatively new with few having even graduated their first class of students (Means et al., 2013). There has been some research published focusing on individual schools (Lynch \&Means, 2012) and research with state based data (Bicer, Navruz, Capraro, \& Capraro, 2014; Navruz, Erdogan, Bicer, Capraro, \& Capraro, 2014; Gourgey, Asiabanpour, Crawford, Gross, \& Herbert, 2009; Young et al., 2011). In this study, we did not report individual schools because cases of individual schools do not "prove that the same effect will be achieved when the concept is implemented at scale" (Means et al., 2013, p. 3). Thus, the present study used Texas Assessment of Knowledge and Skills (TAKS) mathematics scores, state level data, as the metric of achievement. In general, studies reported positive effects for students enrolled in ISHSs.

One study conducted by Young et al. (2011) used state based data to reveal the effects of attending T-STEM academies compared to the effects of attending traditional high schools in Texas. The findings revealed that students who attended T-STEM academies performed better in mathematics and science than did students who attended traditional public high schools; however, the Cohen's $d$ effect sizes of attending TSTEM academies reported by this study ranged from 0.12 to 0.17 . Specifically, $9^{\text {th }}$ graders in T-STEM academies performed better in mathematics compared to $9^{\text {th }}$ graders 
in traditional public schools (Gourgey et al., 2009; Young et al., 2011). Similarly, $10^{\text {th }}$ graders attending T-STEM academies performed better in mathematics and science than did their peers in comparison schools (Young et al., 2011). Young et al. (2011) also reported that $9^{\text {th }}$ graders in T-STEM academies were 1.8 times more likely to meet the TAKS benchmarks in the sections of reading and mathematics than were their counterparts in traditional public schools. Similar results were reported for $10^{\text {th }}$ graders as students in T-STEM academies were 1.5 times more likely than their traditional public school peers to meet the TAKS benchmarks on the reading, mathematics, science, and social science sections. Gourgey et al. (2009) examined students' academic patterns of change over time in T-STEM academies and found that attending T-STEM academies had different effects on students based on their ethnic background and SES. The results revealed that while attending T-STEM academies increased Hispanic students' mathematics scores, a slight decrease was observed for African American and White students. Further, the results showed that students from low-SES backgrounds increased their mathematics scores compared to their previous mathematics scores. Similarly, Bicer et al. (2014a) found that while attending T-STEM academies statistically significantly increased Hispanic students' mathematics mean scores relative to White students' mathematics scores, there was not a statistically significant difference in students' mathematics scores based on their school type (T-STEM academy or traditional public high school). Bicer et al. (2014b) conducted a longitudinal study to characterize patterns of change in students' scores over time, which included both the average trajectory and the variability of each student's trajectories. Results from this 
study revealed that $9^{\text {th }}$ graders who enrolled in T-STEM academies performed higher in mathematics than did their peers in comparison schools; however, no difference was found in their mathematics scores' growth rate. This study also found that female students in T-STEM academies earned higher mathematics TAKS scores than did male students in comparison schools. Navruz et al. (2014) conducted a study to understand how students' TAKS mathematics scores changed after their schools converted to ISHSs. Results from this study revealed that students had a statistically significant increase on their mathematics scores after their school adopted and implemented STEM curriculum and instruction. This study also examined the effects of adopting STEM curriculum on females and males. Evidence from this study showed that "both genders experienced practically important changes" (p. 67).

Overall, research has shown there is a positive effect of attending T-STEM schools on students' mathematics and science achievement (Bicer et al., 2014a; Bicer et al., 2014b; Gourgey et al., 2009; Lynch \& Means, 2012; Navruz et al., 2014; Young et al., 2011). Although all studies regarding STEM schools reported positive effect sizes, some reported small effect sizes, like $d=0.12$ (Young et al., 2011). These findings show the promising effects of T-STEM academies on students' academic achievement, but the studies evaluated the student body as a whole and did not use ethnic background as a moderator. Therefore, these studies do not provide much insight into the achievement of underrepresented subpopulations. However, one study conducted by Gourney et al. (2009) investigated the impact of attending T-STEM academies on students from different ethnic backgrounds and found that Hispanic students' mathematics scores 
increased while a slight decrease was observed for African American and White students. Similarly, Bicer et al. (2014a) found that Hispanic students who were enrolled in T-STEM academies demonstrated better mathematics achievement than did white students who attended traditional public high schools. However, there are no studies that directly test whether Hispanic students who attended T-STEM academies perform better in mathematics than do Hispanic students who attended traditional high schools.

Therefore, the following research questions guide the present study:

1) Did Hispanic students who attended T-STEM academies perform better on mathematics high stakes tests at the end of grade 9 than Hispanic students who attended traditional high?

2) What are the mathematical benefits for Hispanic students who attend T-STEM academies for three years as compared to their Hispanic counterparts who attend traditional public high schools?

\section{Methodology}

\section{Participants and Data Collection}

To determine whether there is a difference in mathematics achievement on a high stakes measures between Hispanic students who attended T-STEM academies and Hispanic students who attended traditional high schools, student and school-level data were obtained from the Texas Education Agency (TEA) website. The research questions will be answered using a quantitative approach with 32 schools, of which 16 were TSTEM academies and 16 were matched non-STEM schools. Only 16 STEM schools of 75 T-STEM academies were selected because these selected schools met the criterion of 
being turned into specialized, inclusive STEM schools before or during the 2008-09 academic year. This criterion was purposefully set to be able to observe the differences of the students based on their school types (T-STEM or traditional high schools) after they attended for at least three years.

The data included student and school information from the state accountability assessment, Texas Assessment of Knowledge and Skills (TAKS), which provided empirical data (2009 to 2011). Reporting reliability coefficients related to students' mathematics performance was used to estimate to what extent the data were consistent (Huck, 2008). The reliability coefficients of mathematics scores on the TAKS assessment were reported as ranging from .82 to .88 (TEA, 2008; Zucker, 2003). The first measurement for the sample was collected when the students were at the end of $9^{\text {th }}$ grade in 2009, and the last measurement for the same students was taken at the end of $11^{\text {th }}$ grade in 2011.

To match students who received three years of education in T-STEM academies with students who received three years of high school education in traditional public schools, schools were first matched by taking into account the school variables reported by TEA. T-STEM academies and traditional public high schools in Texas were matched by applying a nearest neighbor propensity score matching strategy. The following variables were used for propensity score matching: 1) ethnicity (\% of Hispanic students), 2) economic disadvantage status (free lunch, reduced price lunch, other public assistance, and none), 3) English language proficiency (met English language proficiency state standards or did not meet English language proficiency state standards), and 4) school 
mobility rate (expressed as a ratio of the whole school population to students moving into and out of the school in one year). Figure 4 and Figure 5 show the matching was successful demonstrating that selected STEM and matched non-STEM schools were not different on these covariates.

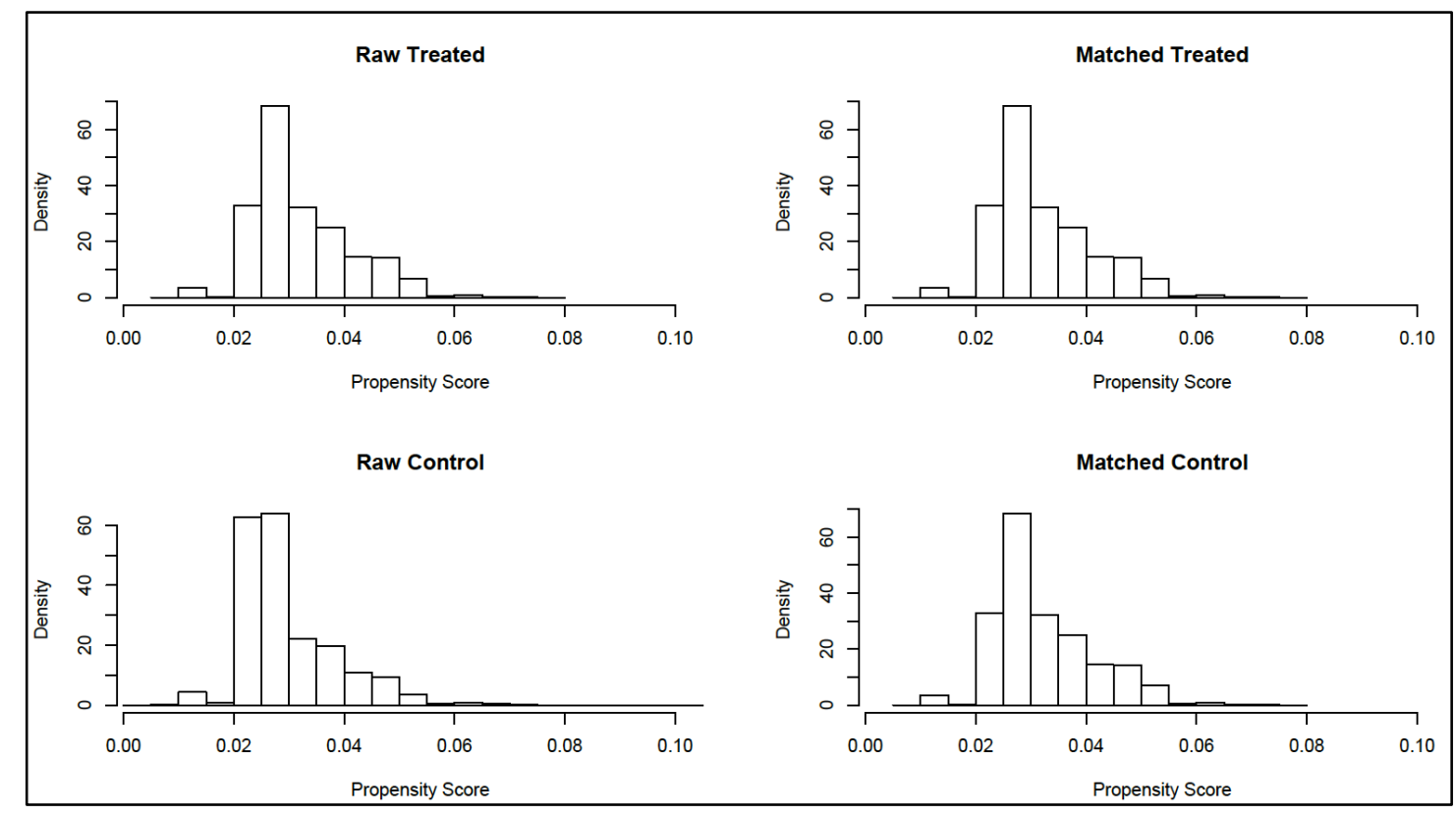

Figure 4. Distribution of Propensity Score Matching. 


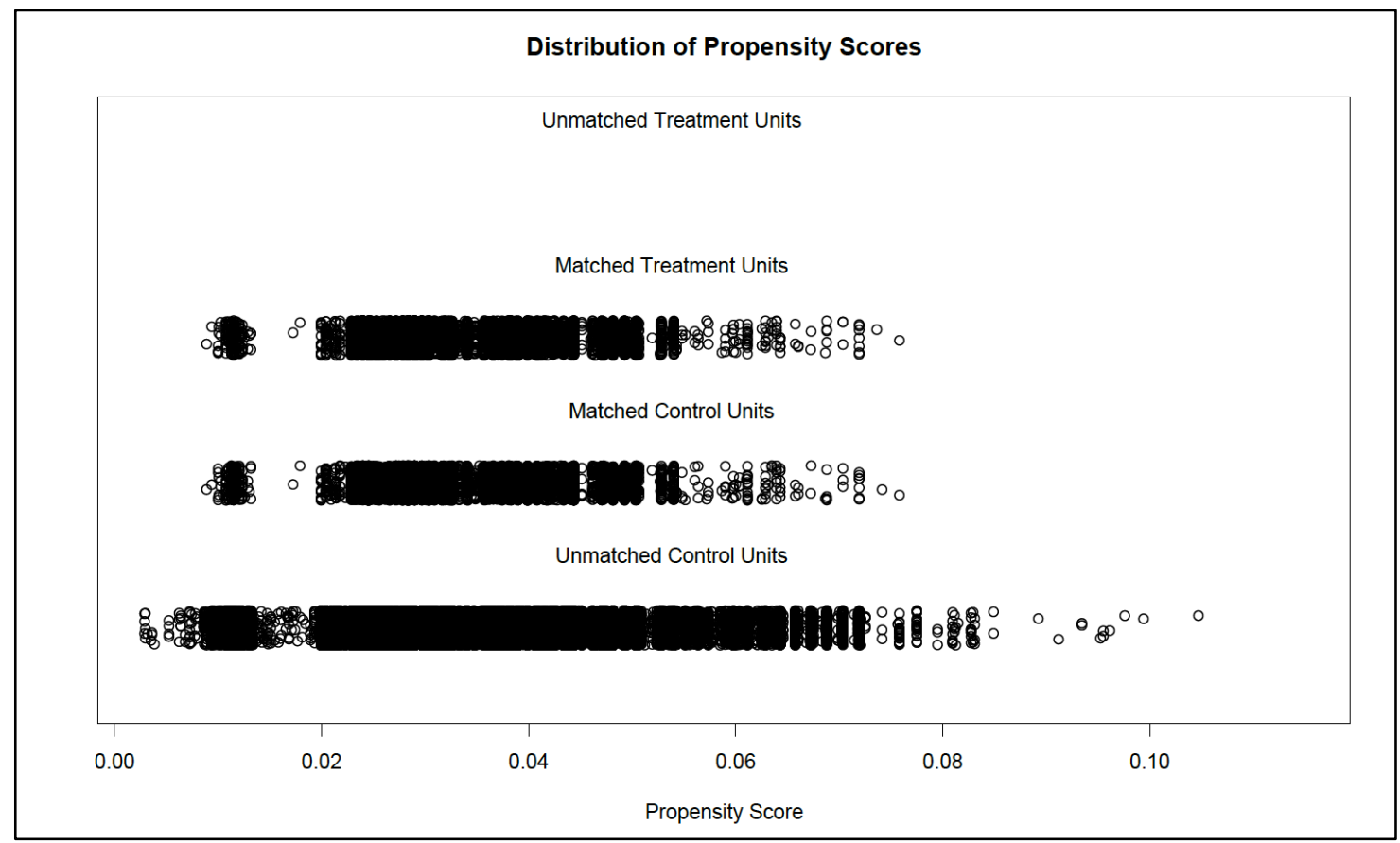

Figure 5. Distribution of Propensity Scores.

The sample in the present study was students (389 from T-STEM academies and 1,036 from traditional public schools) who attended their respective schools for at least three years and received a TAKS mathematics score in 2009 and 2011. Students who did not receive a TAKS mathematics score in either 2009 or 2011 were excluded from the study. Students were also excluded if they were either transferred into T-STEM academies from a non-STEM school or transferred into a non-STEM school from TSTEM schools. These exclusions ensured that participants in the present study who attended T-STEM academies had received at least three years of STEM education and 
were not exposed to any other school interventions during their high school years. To ensure matched comparison schools did not adopt any school level interventions, schools that implemented any intervention (e.g., Early College High School [ECHS] intervention) were excluded from the matched school list. Students' TAKS mathematics scores were used as an outcome estimate of students' mathematics performance. Students' mathematics TAKS scores at the end of $9^{\text {th }}$ grade were modeled as the estimated initial mathematics performance plus the change over time, that is, the rate of change, plus error. Students' gender and SES were added into the model as predictors to determine how students' initial mathematics performance and their growth in mathematics from $9^{\text {th }}$ grade to $11^{\text {th }}$ grade changed by their gender and SES. Further, students' school type was added as a school-level predictor to the model in order to estimate how students' initial mathematics performance and their growth in mathematics changed by their school types as STEM and non-STEM.

\section{Data Analysis}

To examine mathematics performance differences at the end of grade 9 between Hispanic students who attended T-STEM academies and Hispanic students who attended traditional high schools and the growth rate of mathematics performance from grade 9 to grade 11, a three-level growth model in the hierarchical linear modeling (HLM) technique was applied to analyze student and school-level variables simultaneously (Hox, 2002). Level-1 was the repeated measures of students' mathematics scores, which were nested within students. Level-2 was the students who were further nested within schools. Level-3 was the school types as STEM and non-STEM schools. Using a three- 
level model allowed researchers to analyze patterns of change in students' measures over time, which included both average trajectory and the variability of students' trajectories.

\section{Benefits of Using HLM Software}

Applying HLM software yields the same results as other commonly used software (e.g., SAS and ML4) and is appropriate for disentangling multilevel effects (Kreft, DeLeuw, \& Van Der Leeden, 1994). There are many benefits of using HLM software. One benefit of the three-level model in HLM was that this technique provided simultaneous variance estimation of between-school level variables (STEM and nonSTEM schools), within-school level variables (gender and SES), and the variables of repeated measures. The second benefit of using HLM is that it enables researchers to use a larger sample size compared to other quantitative data analysis techniques (e.g., t-test, ANOVA, and MANOVA). In longitudinal examinations, a researcher using HLM does not require each individual to have scores for each point. Therefore, applying HLM in a longitudinal analysis allows researchers to use a large number in their sample size compared to other quantitative analysis such as $t$-test, ANOVA, and ANCOVA, which require researchers to exclude cases having missing data for a time point (Hox, 2002). Another benefit of using HLM software is that yields more accurate estimates compared to other quantitative analyses. This is because other quantitative data analyses like linear or multiple regressions estimate student and school-level variables' variances together, which would inflate standard errors and result in an imprecise estimation of regression coefficients. To avoid an imprecise estimation of regression coefficients, HLM software 
could be employed as it yields a more accurate estimation when students are nested in schools (Cheng, Lam, \& Chan, 2008).

A series of model fit indices were estimated in HLM software, and this procedure resulted in the best model (see Table 7) with specific student and school-level variables. The variables in this study were selected based on theoretical and empirical considerations reported by NRC (2011). After adding each student and school-level variable into the model, statistical significance tests were employed by applying restricted log likelihood $(2 L L)$ to examine whether the variable increased the model fitness (Raftery, 1996). The slopes of student and school-level predictors and their effects were fixed and not allowed to vary randomly if random effects of these variables did not statistically significantly improve the model fitness. The indices of model fitness were based on a Chi-square test, in which deviations' scores and degrees of freedom $(d f)$ were provided by HLM output. To determine whether the slope of the variables had random or fixed effects, deviation scores for a variable in each model (model with fixed effect and model with random effect) were subtracted from each other. Once the intercept and slope of each variable were decided to be "fixed" or "random," the best model (see Table 7) was achieved.

\section{Results}

First, the unconditional model (see Table 6), which did not include any independent variables, was designed and run to estimate what percentage of the total variance was explained by students' individual factors and their school factor. This procedure enabled us to calculate intra-class correlation (ICC). The ICC (Raudnebush \& 
Bryk, 2002) from the level-2 was calculated by the formula, $\rho=\tau_{00} /\left(\tau_{00}+\sigma^{2}\right)$ to be 0.754 . In other words, $75.4 \%$ of the total variability in students' mathematics achievement could be explained by student factors. The ICC (Raudnebush \& Bryk, 2002) from the level-3 was also calculated by the formula, $\rho=\mathrm{u}_{00} /\left(\mathrm{u}_{00+} \tau_{00}+\sigma^{2}\right)$ to be 0.112 . Thus $11.2 \%$ of the total variability in students' mathematics achievement could be explained by school factors.

Table 6

Unconditional or Base Model

\begin{tabular}{ll}
\hline Level & Model \\
\hline Level-1 & MATH $_{i j k}=\pi_{0 j k}+e_{i j k}$ \\
Level-2 & $\pi_{0 j k}=\beta_{00 k}+r_{0 j k}$ \\
Level-3 & $\beta_{00 k}=\gamma_{000}+u_{00 k}$ \\
\hline
\end{tabular}


Second, based on a theoretical and empirical consideration reported by NRC (2011) and prior research, each student-level predictor (gender and SES) and schoollevel predictor (school types) was added to the model and evaluated for statistical significance. The slopes of student-and school-level variables were fixed if random effects of these variables were not statistically significant in improving the model fitness. This procedure resulted in best models for specific students and school predictors. 
Table 7

The Best Model

\begin{tabular}{ll}
\hline Level & Model \\
\hline Level-1 & MATH $_{i j k}=\pi_{0 j k}+\pi_{1 j k} *\left(T I M E_{i j k}\right)+e_{i j k}$ \\
Level-2 & $\pi_{0 j k}=\beta_{00 k}+\beta_{01 k} *\left(F E M A L E_{j k}\right)+$ \\
& $\beta_{02 k} *\left(S E S_{j k}\right)+r_{0 j k}, \pi_{1 j k}=\beta_{10 k}+$ \\
& $\beta_{11 k} *\left(F E M A L E_{j k}\right)+\beta_{12 k} *\left(S E S_{j k}\right)+r_{1 j k}$ \\
& $\beta_{00 k}=\gamma_{000}+\gamma_{001}\left(S T E M 9_{k}\right)+u_{00 k}, \beta_{01 k}$ \\
& $=\gamma_{010}+\gamma_{011}\left(S T E M 9_{k}\right)+u_{01 k}, \beta_{02 k}=$ \\
& $\gamma_{020}+\gamma_{021}\left(S T E M 9_{k}\right)+u_{02 k}, \beta_{10 k}=\gamma_{100}$ \\
& $+\gamma_{101}\left(S T E M 9_{k}\right)+u_{10 k}, \beta_{11 k}=\gamma_{110}+$ \\
& $\gamma_{111}\left(\operatorname{STEM}_{k}\right)+u_{11 k}, \beta_{12 k}=\gamma_{120}+$ \\
& $\gamma_{121}\left(\operatorname{STEM}_{k}\right)+u_{12 k}$ \\
\hline
\end{tabular}

Third, in order to determine how much variance was explained in Level-1 after adding the predictor of "time," the proportion of variability accounted (PVAC), or $R \& B$ $R^{2}$ (Raudnebush \& Bryk, 2002), in Level-1 was calculated by the formula, pvac $=\left(\sigma_{\text {base }}^{2}-\right.$ $\left.\sigma_{\text {augmented1 }}{ }^{2}\right) / \sigma_{\text {base }}{ }^{2}$ and 0.199 . The augmented model was gathered by adding time as a 
predictor to the base model. In other words, $19.9 \%$ of variability of students' mathematics achievement in Level-1 was accounted for by the correlation among students' three years' repeated measures of mathematics scores (time). Because the main aim of the present study was to examine how participating in STEM schools affects students' mathematics growth, the proportion of Level-3 variability was calculated by the formula, pvac $=\left(\mathrm{u}_{00(\text { (base })}-\mathrm{u}_{00(\text { augmented2) }}\right) / \mathrm{u}_{00(\text { (base) }}($ Raudnebush $\&$ Bryk, 2002) to be 0.65. The augmented model was gathered by adding STEM as a school-level predictor to the base model. In other words, $65 \%$ of variance between school differences in mean mathematics achievement was accounted for by students' school types (e.g., STEM high schools and non-STEM high schools).

After examining how much variance was accounted for by the certain student and school-level predictors, the results were examined as students' initial mathematics scores at the end of $9^{\text {th }}$ grade, and students' growth rate of mathematics achievement from grade 9 to grade 11 . To address the two research questions, the results section addresses aspects of the questions across two sections: 1) differences in mathematics scores after students began participating in STEM schools at the end of grade 9, and 2) differences in the growth rate of mathematics achievement from grade 9 to grade 11.

\section{Differences in Mathematics Scores at the end of Grade 9 (see in table 8)}

The initial predicted mean mathematics score of our reference baseline group (male, high-SES, and non-STEM) $\left(\gamma_{000}=2164.7\right)$ was statistically significant $(p<.05)$. The difference between T-STEM academies and non-STEM schools $\left(\gamma_{001}=107.5\right)$ was 
statistically significant $(p<.05)$, indicating that Hispanic students in T-STEM academies tend to achieve higher mathematics scores than Hispanic students in non-STEM schools at the end of $9^{\text {th }}$ grade when controlling for gender and SES.

Table 8

Final Estimation of Fixed Effects for Intercept

\begin{tabular}{cccccc}
\hline Fixed Effects & Coefficients & $S E$ & t-ratio & $N$ & $p$ \\
\hline Intercept, $\gamma_{000}$ & 2164.7 & 20.2 & 106.8 & 1425 & $<0.05$ \\
(Intercept)X(STEM), $\gamma_{001}$ & 107.5 & 27.4 & 3.9 & 1425 & $<0.05$ \\
FEMALE, $\gamma_{010}$ & 21.2 & 9.9 & 2.140 & 1425 & $<0.05$ \\
(FEMALE)X(STEM), $\gamma_{011}$ & -48.2 & 20.9 & -2.2 & 1425 & $<0.05$ \\
SES, $\gamma_{020}$ & -43.4 & 17.5 & -2.4 & 1425 & $<0.05$ \\
(SES)X(STEM), $\gamma_{021}$ & 33.8 & 24.3 & 1.3 & 1425 & $>0.05$ \\
\hline
\end{tabular}

We were also interested in how Hispanic students in T-STEM academies and non-STEM schools compared by gender in terms of their mathematics achievement. The effect for gender on Hispanic students' predicted mean mathematics score $\left(\gamma_{010}=21.2\right)$ was statistically significant $(p<.05)$, which indicated that when controlling for SES there was a difference in mathematics achievement at the end of grade 9 between female 
and male Hispanic students who were enrolled in non-STEM high schools. Female students in non-STEM schools achieved higher than males in non-STEM schools at the end of grade 9 when controlling for SES. To understand differences between females and males when schools changed from non-STEM to STEM, the interaction effect of gender was added into the model. The effect for STEM schools $\left(\gamma_{011}=-48.2\right)$ was statistically significant $(p<.05)$, which demonstrated that female students in T-STEM academies performed lower on TAKS mathematics than male students in T-STEM schools at the end of grade 9 when controlling for SES. In non-STEM schools, females scored 21.2 points higher than did males, and in T-STEM schools female scored (21.2$48.2=-27)$ points lower than males.

The last predictor in the final model was SES. The effect of SES on Hispanic students' mathematics achievement in non-STEM schools $\left(\gamma_{020}=-43.4\right)$ was statistically significant $(p<.05)$, which indicated that there was a statistically significantly difference between low- and high-SES Hispanic students in non-STEM schools on their mathematics achievement at the end of grade 9 when controlling for gender. Students who were from low-SES backgrounds in non-STEM schools performed lower in mathematics than high-SES students from high-SES backgrounds at the end of grade 9. However, the interaction effect of SES and school type $\left(\gamma_{021}=33.8\right)$ was not statistically significant $(p>.05)$, which indicated that, controlling for gender, the mean mathematics achievement difference between high-SES Hispanic and low-SES Hispanic students did not change when schools changed from non-STEM to STEM at the end of grade 9. 


\section{Differences in the Growth Rate of Mathematics Achievement (see in Table 9)}

Results indicated statistically significant differences in the growth rate of mathematics achievement for all Level-2 predictors. However, there were no statistically significant interaction effects other than the interaction effect of gender and school type.

Table 9

Final Estimation of Fixed Effects for Time

\begin{tabular}{cccccc}
\hline Fixed Effects & Coefficients & $S E$ & t-ratio & $N$ & $p$ \\
\hline Intercept, $\gamma_{100}$ & 31.5 & 6.4 & 4.8 & 1425 & $<0.05$ \\
(Intercept)X(STEM), $\gamma_{101}$ & -11.4 & 9.9 & -1.1 & 1425 & $>0.05$ \\
FEMALE, $\gamma_{110}$ & -7.5 & 2.3 & -3.2 & 1425 & $<0.05$ \\
(FEMALE)X(STEM), $\gamma_{111}$ & 16.4 & 6.4 & 2.5 & 1425 & $<0.05$ \\
SES, $\gamma_{120}$ & 11.5 & 2.7 & 4.1 & 1425 & $>0.05$ \\
(SES)X(STEM), $\gamma_{121}$ & -21.3 & 9.9 & -2.1 & 1425 & $>0.05$ \\
\end{tabular}


The average annual growth rate of Hispanic students' mathematics achievement for our reference group (male, high-SES in non-STEM schools), $\gamma_{100}=31.5$, was statistically significant $(p<.05)$, which indicated an increase of 31.5 points per year. However, the interaction effect of time and school type $\left(\gamma_{101}=-11.4\right)$ was not statistically significant $(p>.05)$ illustrating that controlling for gender and SES, there was not a statistically significant difference found in Hispanic students' mathematics achievement growth rate when compared by their school type.

The average annual growth rate of mathematics achievement differences between male and female Hispanic students in non-STEM schools when controlling for SES ( $\gamma_{110}$ $=-7.5)$ was statistically significant $(p<.05)$ indicating that the mathematics achievement growth rate of female students was 7.5 points lower than male students' mathematics achievement growth rate. In addition, the interaction effect of gender and school type $\left(\gamma_{111}=16.4\right)$ was statistically significant $(p<.05)$ illustrating that the mathematics achievement growth rate of female Hispanic students in T-STEM schools was statistically significantly higher than the mathematics achievement growth of male Hispanic students in T-STEM schools when controlling for SES. In other words, in nonSTEM schools, female students mathematics achievement growth rate was -43.4 points lower than male students; in T-STEM schools, female students' mathematics growth rate was 8.9 points higher than for males.

The last predictor in the final model was SES. The effect of SES on Hispanic students' mathematics achievement growth rate $\left(\gamma_{120}=11.53\right)$ was not statistically significant $(p>.05)$ indicating that there was not a statistically significant difference 
between low-SES students and high-SES students in their mathematics achievement growth rate. In addition, the interaction effect of SES and school type $\left(\gamma_{121}=-21.3\right)$ was also not statistically significant $(p>.05)$, which indicated that the mathematics achievement growth rates of high-SES Hispanic students and low-SES students did not differ when compared by their school type.

\section{Conclusion}

The purpose of the present study was to examine how Hispanic students' performance on the TAKS mathematics sections differed in terms of their school type as STEM and non-STEM schools. Previous studies, such as Bicer et al. (2015) and Young et al. (2011), have compared students' mathematics performance in terms of their school type as STEM and non-STEM schools. Specifically, Bicer et al. (2014) examined the mathematics achievement gap between students who are underrepresented and enrolled in STEM schools and students who were White and enrolled in traditional high schools. However, no studies thus far have tested mathematics achievement differences between Hispanic students who enroll in STEM schools and Hispanic students who enroll in traditional public schools, which makes this study unique. The main objective for examining Hispanic students' TAKS mathematics growth rate was to determine the

effect of attending T-STEM academies after students completed $9^{\text {th }}, 10^{\text {th }}$, and $11^{\text {th }}$ grades in T-STEM academies compared to their corresponding Hispanic peers who attended traditional public high schools. The reason why we are interested in students' mathematics achievement growth rate is because students may attend T-STEM academies due to their prior interest in STEM disciplines. Although ISHSs accept 
students regardless of their previous academic achievement, self-selection might be an indicator of students' prior interest in STEM disciplines. That is exactly why our focus is on students' mathematics achievement growth rate from grade 9 to grade 11 rather than on their mathematics scores at the end of grade 9 . The results of the present study revealed that there were no differences in Hispanic students' mathematics achievement growth rate in T-STEM academies compared to Hispanic students' mathematics achievement growth rate in traditional public high schools. However, in terms of gender, the results indicated that female Hispanic students outperformed male students in TSTEM academies in terms of their mathematics achievement growth. This was not the same story for non-STEM schools because female Hispanic students performed lower than male students' in terms of their mathematics growth rate. This finding showed that participating in STEM schools was more helpful for female Hispanic students than for Hispanic male students. This finding is consistent with prior work by Bicer et al. (2015) that suggested that female Hispanic students increased their mathematics scores on highstakes tests when they enrolled in T-STEM academies. This might be explained by the two school factors identified by Gainen (1995) that would influence students' mathematics success in non-STEM schools.

Two school factors, according to Gainen (1995), that influence student performance include the nature of the classroom environment and the type of instructional techniques implemented by the teachers. The first school factor is a highly competitive classroom environment. Female Hispanic students in highly competitive environments might be discouraged to participate during mathematics instruction (Chapa 
\& De La Rosa, 2006). Due to the inclusive nature of T-STEM academies, the student body is not only comprised of students who were highly interested and motivated in STEM disciplines. Thus, this inclusive environment, while seeking to motivate students to pursue STEM fields, does not necessarily create a highly competitive environment inherent within selective STEM schools. The second school factor is the level of engaging instructional practices. T-STEM academies integrate into their mathematics and science classrooms innovative instructional practices such as inquiry-based learning, project-based learning (PBL), and problem-based learning (Bicer et al., 2014; Navruz et al., 2014; Young et al., 2011). All of these instructional techniques emphasize the importance of a student-centered learning environment (Means et al., 2013). It is possible that female Hispanic students may learn mathematics more effectively when these innovative, student-centered, instructional pedagogies are employed. This can be supported by Hurtodo et al. (2006) who found that female Hispanic students performed better in mathematics when they actively participated in their own learning rather than when they received traditional instruction. In addition to these school factors, the cultural makeup of ISHSs can contribute to the success of female Hispanic students on high-stakes tests.

Improved achievement among female Hispanics in T-STEM academies may be explained by the cultural congruity of their student bodies. Cole and Espinoza (2008) showed that female Hispanic students achieved their academic goals better when they had cultural congruity in their schools. T-STEM academies require that $50 \%$ of their student enrollment comes from underrepresented subpopulations, and Hispanics 
represent the largest group fitting this criterion. Therefore, a large portion of the students attending T-STEM academies is Hispanic, and this creates cultural congruity. All of these factors may lead to the conclusion that female Hispanic students in T-STEM academies performed better than Hispanic students in traditional public schools due, at least in part, to the unique design elements and implementation processes of T-STEM academies.

The findings of the present study are important for two reasons: 1) NRC (2011) reported that it is essential to increase the number of underrepresented students who major in STEM to maintain the United States' scientific leadership and economic power; and 2) by the end of 2050, the number of Hispanic students aged between 5 and 17 will rise to more than 20 million (Chapa \& De La Rosa, 2006). This rapid change in the nation's demographics also shows how female Hispanic students play a major role in achieving the nation's STEM education goals. The present study suggests that "the number of STEM schools need to be extended especially in high Hispanic-population areas" (Bicer et al., 2014) in Texas. Establishing more T-STEM academies may increase female Hispanic students' mathematics achievement through the unique design elements and implementation processes of these schools. 


\section{CHAPTER V}

\section{SUMMARY AND DISCUSSION}

The main focus of this dissertation was the type of schools that can help students increase their mathematics achievement. The general findings revealed that participating in T-STEM academies could contribute to Hispanic students, especially for female Hispanic students, mathematics achievement. There might be several school factors influencing Hispanic students' mathematics achievement in T-STEM academies. Gainen (1995) noted two school factors explaining the reasons why Hispanic students performed better in T-STEM academies compared to their peers in traditional public high schools. The first factor was about whether a school or classroom had a collaborative or competitive environment. Chapa and De La Rosa (2006) found that Hispanic students in highly competitive environments might be discouraged to participate during mathematics instruction or activities (Chapa \& De La Rosa, 2006). In the light of this research and the inclusive nature of T-STEM academies, it can be concluded that participating in T-STEM academies provides Hispanic students' with a collaborative environment, which in turn may foster their mathematics achievement.

The second school factor is the level of engaging classroom practices.

Mathematics instructors in T-STEM academies implemented innovative instructional practices such as inquiry-based learning, project-based learning (PBL), and problembased learning (Bicer et al., 2014; Navruz et al., 2014; Young et al., 2011). All of these instructional techniques emphasize the importance of a student-centered learning environment (Means et al., 2013). The results from this dissertation study yielded that 
female Hispanic students experienced enhanced mathematics performance as indicated by their TAKS mathematics test scores. It is possible that female Hispanic students may learn mathematics more effectively when these innovative, student-centered, instructional pedagogies are employed in T-STEM academies. Hurtodo et al. (2006) have already reported that female Hispanic students performed better in mathematics when they actively participated in their own learning rather than when they received traditional instruction. The curriculum and instruction strategies (group work, active engagement, hands-on activities, real life applications, cooperative and collaborative learning, etc.) in T-STEM academies could have provided a framework for greater engagement (Myers \& Fouts, 1992; Oakes, 1990). This result also could lead us to the conclusion that with the implementation of proper strategies in STEM classrooms, female students' achievement and interest in STEM disciplines could be increased. Increasing female students' achievement and interest in STEM disciplines would lead them to pursue STEM careers, which will close the gap for females in the STEM pipeline (Blickenstaff, 2005) and help toward increasing the number of people who are in the STEM workforce. In the light of previous research and this dissertation's findings, it can be concluded that female Hispanic students in T-STEM academies may have more positive attitudes towards mathematics when presented with opportunities from innovative mathematics instructional techniques.

In addition to these school factors, the cultural makeup of ISHSs can contribute to the success of female Hispanic students on high-stakes tests. Improved achievement among female Hispanics in T-STEM academies may be explained by the cultural 
congruity of their student bodies. Cole and Espinoza (2008) showed that female Hispanic students achieved their academic goals easier when they had cultural congruity in their schools. T-STEM academies require that $50 \%$ of their student enrollment comes from underrepresented subpopulations, and Hispanics represent the largest group fitting this criterion. Therefore, a large portion of the students attending T-STEM academies are Hispanic, and this creates cultural congruity. All of these factors may lead to the conclusion that female Hispanic students in T-STEM academies performed better than Hispanic students in traditional public schools due, at least in part, to the unique design elements and implementation processes of T-STEM academies.

The findings from this dissertation study are important primarily for two reasons. First, it is essential to increase the number of underrepresented students who major in STEM to maintain the United States' scientific leadership and economic power (NRC, 2011). Second, by the end of 2050, the number of Hispanic students between the ages of 5 and 17 will rise to more than 20 million (Chapa \& De La Rosa, 2006). This rapid change in the nation's demographics also shows how Hispanic students can play a major role in achieving the nation's STEM education goals. The present study suggests that "the number of STEM schools need to be extended especially in high Hispanicpopulation areas" (Bicer et al., 2014) in Texas. Establishing more T-STEM academies may increase female Hispanic students' mathematics achievement through the unique design elements and implementation processes of these schools. 


\section{REFERENCES}

America COMPETES Act, H. R. $2272110^{\text {th }}$ Congress (2007).

Ashlock, B. R. (2005). Error patterns in computation: Using error patterns to improve instruction. Upper Saddle River, NJ: Prentice Hall

Avery, S., Chambliss, D., Pruiett, R., \& Stotts, J. L. (2010). T-STEM academy design blueprint, rubric, and glossary. Retrieved from http://www.edtx.org/uploads/general/pdf-downloads/miscPDFs/2011_TSTEMDesignBlueprint.pdf

Beiber, M. E. (2008). Literature overview: Motivational factors in STEM: Interest and self-concept. SWE-AWE CASEE Overviews. Retrieved from http://www.engr.psu.edu/awe/misc/ARPs/ARP_SelfConcept_Overview_122 208.pdf

Bicer, A., Capraro, M. M., \& Capraro, R. M. (2013). The effects of parent's SES and education level on students' mathematics achievement: Examining the mediation effects of parental expectations and parental communication. The Online Journal of New Horizons in Education, 3(4), 89-97.

Bicer, A., Capraro, R.M, \& Capraro, M. M. (2013). Integrating writing into mathematics classroom to increase students' problem solving skills. International Online Journal of Educational Science, 5(2), 361-369.

Bicer, A., Navruz, B., Capraro, R. M., \& Capraro, M.M. (2014). STEM schools vs. non-STEM schools: Comparing students' mathematics state based test performance. International Journal of Global Education, 3(3), 8-18. 
Bicer, A., Navruz, B., Capraro, R. M., Capraro, M. M., Oner, T. A., \& Boedeker, P. (2015). STEM schools vs. non-STEM schools: Comparing students' mathematics growth rate on high-stakes test performance. International Journal of New Trends in Education and Their Implications, 6(1), 138-150.

Blickenstaff, J. C. (2005). Women and science careers: Leaky pipeline or gender filter? Gender and Education, 17(4), 369-386.

Bloom, B. S. (Ed.). (1985). Developing talent in young people. New York, NY: Ballantine Books.

Brody, L. (2006, September). Measuring the effectiveness of STEM talent initiatives for middle and high school students. Paper presented at the meeting of the National Academies Center for Education, in collaboration with the American Psychological Association, U.S. Department of Education, National Institutes of Health, National Science Foundation, and National Commission on Teaching and America's Future, Washington, DC. Retrieved from http://www7.nationalacademies.org/cfe/Linda\%20Brody\%20 Think\%20Piece.pdf

Burton-P., E., E., Lynch, S. J., Behrend, T. S., \& Means, B. B. (2014). Inclusive STEM high school design: 10 critical components. Theory Into Practice, $53(1), 64-71$.

Buxton, C. (2001). Exploring science-literacy-in-practice: Implementations for scientific literacy from an anthropological perspectives. Electronic Journal 
in Science and Literacy Education, 1(1). Retrieved from

http://sweeneyhall.sjsu.edu/ejlts/

Calkins, L. N., \& Welki, A. (2006). Factors that influence choice of major: Why some students never consider economics. International Journal of Social Economics, 33(8), 547-564.

Capraro, M. M., Capraro, R. M., \& Lewis, C. (Eds.) (2013). Improving urban schools: Equity and access in K-16 STEM education for all students. New York, NY: Information Age.

Capraro, R. M., Capraro, M. M., \& Morgan, J. (Eds.) (2013). Project-based learning: An integrated science, technology, engineering, and mathematics (STEM) approach (2 ${ }^{\text {nd }}$ Edition, pp. 1-214). Rotterdam, The Netherlands: Sense.

Castro, B. T. (2013). Hispanic now majority in Texas public schools, districts assess if they are ready for change. Retrieved from http://www.huffingtonpost.com/2013/06/12/hispanics-majority-texasschools_n_3427239.html

Chapa, J., \& De La Rosa, B. (2006). The problematic pipeline demographic trends and Latino participation in graduate Science, Technology, Engineering, and Mathematics programs. Journal of Hispanic Higher Education, 5(3), 203221. 
Cole, D., \& Espinoza, A. (2008). Examining the academic success of Latino students in science technology engineering and mathematics (STEM) majors. Journal of College Student Development, 49(4), 285-300.

Committee on Prospering in the Global Economy of the 21st Century: An Agenda for American Science and Technology, National Academy of Sciences, National Academy of Engineering, \& Institute of Medicine (US). (2007). Rising above the gathering storm: Energizing and employing America for a brighter economic future. Washington, DC: National Academies Press.

Crisp, G., Nora, A., \& Taggart, A. (2009). Student characteristics, pre-college, college, and environmental factors as predictors of majoring in and earning a stem degree: An analysis of students attending a Hispanic serving institution. American Educational Research Journal, 46(4), 924-942.

Duncan, A. (2012). Fighting the wrong education battles. Remarks of secretary Duncan at the Askwith Forum, Harvard Graduate School of Education, 2(7), 2012.

Educate Texas. (2014). T-STEM academy design blueprint. Retrieved from http://www.edtx.org/uploads/general/pdf-downloads/misc PDFs/EDTX_TSTEM_Academyblueprint.pdf

Executive Office of the President. (2009). Women and girls in science, technology, engineering, and math (STEM). Retrieved from http://www.whitehouse.gov/ostp/women 
Gainen, J. (1995). Barriers to success in quantitative gatekeeper courses. In J. Gainen \& E. W. Willemson (Eds.), Fostering student success in quantitative gateway courses (New Direction for Teaching and Learning, 61). San Francisco, CA: Jossey-Bass.

Gonzalez, H. B., \& Kuenzi, J. J. (2012). Science, technology, engineering, and mathematics (STEM) education: A primer. Congressional Research Service. Retrieved from http://www.fas.org/sgp/crs/misc/R42642.pdf

Gourgey, H., Asiabanpour, B., Crawford, R., Grasso, A., \& Herbert, K. (2009).

Case study of manor new tech high school: promising practices for comprehensive high schools. Retrieved from http://www.newtechnetwork.org/sites/default/files/dr/manornewtechcasestud y.pdf

Han, S. Y., Capraro, R. M., \& Capraro, M. M. (2014). How science, technology, engineering, and mathematics (STEM) project based learning (PBL) affects high, middle, and low achievers differently: The impact of student factors on achievement. International Journal of Science and Mathematics Education, 13(5), 1089-1113.

Hill, C. J., Bloom, H. S., Black, A. R., \& Lipsey, M. W. (2008). Empirical benchmarks for interpreting effect sizes in research. Child Development Perspectives, 2(3), 172-177.

Hox, J. J. (2002). Multilevel analysis: Techniques and applications. Mahwah, NJ: Erlbaum. 
Hurtado, S., Cerna, O. S., Chang, J. C., Saenz, V. B., Lopez, L. R., Mosqueda, C., et al. (2006). Aspiring scientist: Characteristics of college freshman interested in the biomedical and behavioral sciences. Los Angeles, CA: Higher Education Research Institute.

Kuechler, W. L., McLeod, A., \& Simkin, M. G. (2009). Why don't more students major in IS? Decision Sciences Journal of Innovative Education, 7(2), 463488.

Lacey, T. A., \& Wright, B. (2009). Occupational employment projections to 2018. Monthly Labor Review, 432(11), 82-123.

Lynch, S. J., \& Means, B. B. (2012, April). Inclusive STEM high schools: Improving educational opportunity and the economy in the U.S. Paper presented at the annual meeting of AERA (April, 2012), Vancouver, BC.

Means, B., Confrey, J., House, A., \& Bhanot, R. (2008). STEM high schools: Specialized science technology engineering and mathematics secondary schools in the US (Bill and Melinda Gates Foundation Report). Retrieved from http://www.hsalliance.org/stem/index.asp.

Means, B., House, A., Young, V., Wang, H., \& Lynch, S. (2013). Expanding access to STEM-focused education: What are the effects [White paper]? Washington, DC: SRI International.

Myers, R. E., \& Fouts, J. T. (1992). A cluster analysis of high school science classroom environments and attitude toward science. Journal of Research in Science Teaching, 29(9), 929-937. 
National Academy of Science, National Academy of Engineering, and Institute of Medicine. (2007). Rising above the gathering storm: Energizing and employing America for a brighter economic future. Washington, DC: The National Academies Press.

National Research Council. (1996). National science education standards. Washington, DC: National Academy Press.

National Research Council. (2009). Successful K-12 STEM education: Identifying effective approaches in science, technology, engineering, and mathematics. Washington, DC: NAP.

National Research Council. (2011). Successful K-12 STEM education: Identifying effective approaches in science, technology, engineering, and mathematics. Washington, DC: NAP.

National Science Board. (2010). Preparing the next generation of STEM innovators: Identifying and developing our nation's human capital. Retrieved from http://www.nsf. gov/nsb/publications/2010/nsb1033.pdf

National Science Board. (2007). National action plan: For addressing the critical needs of the U.S. science, technology, engineering, and mathematics education system. Retrieved from http://www.nsf.gov/nsb/documents/2007/stem_action.pdf

National Science Foundation. (2010). Integrated postsecondary education data system completions survey. Retrieved from https://caspar.nsf.gov/ 
Navruz, B., Erdogan, N., Bicer, A., Capraro, R. M., \& Capraro, M. M. (2014). Would a STEM school 'by any other name smell as sweet'? International Journal of Contemporary Educational Research, 1(2), 67-75.

Oakes, J. (1990). Multiplying inequalities: The effects of race, social class, and tracking on opportunities to learn mathematics and science. Santa Monica, CA: The RAND Corporation.

Oner, A. T., Navruz, B., Bicer, A., Peterson, C. A., Capraro, R. M., \& Capraro, M. M. (2014). T-STEM academies' academic performance examination by education service centers: A longitudinal study. Turkish Journal of Education, 3(4), 40-51.

President's Council of Advisors on Science and Technology. (2010). Prepare and inspire: K-12 education in science, technology, engineering, and math (STEM) for America's future. Washington, DC. Retrieved from http://www.whitehouse.gov/sites/default/files/microsites/ostp/pcast-stem-edfinal.pdf

Pyryt, M. C. (2000). Talent development in science and technology. In K. A. Heller, F. J. Monks, R. J. Sternberg, \& R. F. Subotnik (Eds.), International handbook of giftedness and talent (2nd ed., pp. 427-437). Oxford, UK: Elsevier.

Roberts, K. (1968). The entry into employment: An approach towards a general theory. Sociological Review, 16, 165-184. 
Sahin, A. (2013). STEM clubs and science fair competitions: Effects on postsecondary matriculation. Journal of STEM Education: Innovations \& Research, 14(1), 5-11.

Sahin, A., Erdogan, N., Morgan, J., Capraro, M. M., \& Capraro, R. M. (2013). The effects of high school course taking and SAT scores on college major selection. Sakarya University Journal of Education, 2(3), 96-109.

Schmidt, W. H. (2011, May). STEM reform: Which way to go? Paper presented at the National Research Council Workshop on Successful STEM Education in K-12 Schools. Retrieved from http://www7.nationalacademies.org/bose/STEM_Schools_Workshop_Paper _Schmidt.pdf

Scott, C. E. (2009). Unpublished doctoral dissertation. A comparative case study of characteristics of science, technology, engineering, and mathematics (STEM) focused high schools. Retrieved from Proquest (AAT 3365600).

Stotts, J. L. (2011). The STEM initiative-a multiple case study of mission-driven leadership in two school implementing STEM in Texas: Successes, obstacles, and lessons learned (Doctoral dissertation). Retrieved from ProQuest. (UMI: 3454109)

Subotnik, R. F., Duschl, R., \& Selmon, E. (1993) Retention and attrition of science talent: A longitudinal study of Westinghouse Science Talent Search winners. International Journal of Science Education, 15(1), 61-72. 
Subotnik, R. F., Tai, R. H., Rickoff, R., \& Almarode, J. (2010). Specialized public high schools for science, mathematics, technology and the STEM pipeline: What do we know now and what will we know in five years? Roeper Review, 32, 7-16.

Tai, R. H., Liu, C. Q., Maltese, A. V., \& Fan, X. (2006). Planning early for careers in science. Science, 312(5777), 1143-1144.

Texas Education Agency. (2013). Texas science, technology, engineering, and mathematics initiative (T-STEM). Retrieved from http://www.tea.state.tx.us/.

Texas Education Agency. (2014). Texas science, technology, engineering, and mathematics initiative (T-STEM). Retrieved from http://www.tea.state.tx.us/

Thomas, J., \& Williams, C. (2009). The history of specialized STEM schools and the formation and role of the NCSSSMST. Roeper Review, 32(1), 17-24.

U.S. Department of Labor. (2007). The STEM workforce challenge: The role of the public workforce system in a national solution for a competitive science, technology, engineering, and mathematics (STEM) workforce. Washington, DC: Author. Retrieved from http://www.doleta.gov/youth_services/pdf/STEM_Report_4\%2007.pdf

Young, H. (2005). Secondary education systematic issues: Addressing possible contributors to a leak in the science education pipeline and potential solutions. Journal of Science Education \& Technology, 14(2), 205-216.

Young, V. M., House, A., Wang, H., Singleton, C., \& Klopfenstein, K. (2011, May). Inclusive STEM schools: Early promise in Texas and unanswered 
questions. Paper presented at the National Research Council Workshop on Successful STEM Education in K-12 Schools. Retrieved from http://www7.nationalacademies.org/bose/STEMSchools_Workshop_Paper_ Young.pdf 


\section{APPENDIX A}

Final Estimation of Level-1 and Level-2 Variance Components for Chapter IV

\begin{tabular}{rrrrcr}
\hline \multirow{2}{*}{ Random Effect } & $\begin{array}{r}\text { Standard } \\
\text { Deviation }\end{array}$ & $\begin{array}{r}\text { Variance } \\
\text { Component }\end{array}$ & $d . f$. & $\chi^{2}$ & $p$-value \\
\hline INTRCPT1, $r_{0}$ & 186.67 & 34847.53 & 1451 & 9429.15 & $<.05$ \\
TIME slope, $r_{l}$ & 32.26 & 1040.75 & 1451 & 1758.83 & $<.05$ \\
level-1, $e$ & 84.25 & 7099.34 & & & \\
\hline
\end{tabular}




\section{APPENDIX B}

Final Estimation of Level-3 Variance Components for Chapter IV

\begin{tabular}{lrrrrr}
\hline Random Effect & $\begin{array}{r}\text { Standard } \\
\text { Deviation }\end{array}$ & $\begin{array}{r}\text { Variance } \\
\text { Component }\end{array}$ & d.f. & $\chi^{2}$ & $p$-value \\
\hline INTRCPT1/INTRCPT2, $u_{00}$ & 39.99 & 1599.62 & 16 & 16.35 & $<.05$ \\
INTRCPT1/ FEMALE, $u_{01}$ & 21.52 & 463.22 & 16 & 15.91 & $>.05$ \\
INTRCPT1/ SES, $u_{02}$ & 22.10 & 488.74 & 16 & 12.61 & $>.05$ \\
TIME/INTRCPT2, $u_{10}$ & 13.74 & 188.82 & 16 & 13.30 & $>.05$ \\
TIME/ FEMALE, $u_{11}$ & 2.98 & 8.89 & 16 & 8.53 & $>.05$ \\
TIME/ SES,$u_{12}$ & 4.07 & 16.60 & 16 & 9.53 & $>.05$ \\
\hline
\end{tabular}

